\title{
$N$-取代-1,2,3-三氮唑化合物的合成研究进展
}

\author{
刘启顺 ${ }^{a}$ 吕玉芬 ${ }^{a}$ 鲍鹏丽*,a 岳会兰 ${ }^{*}, b$ 魏 伟 $*, a, b$ \\ $\left({ }^{a}\right.$ 曲阜师范大学化学与化工学院 山东曲阜 273165) \\ $\left({ }^{b}\right.$ 中国科学院西北高原生物研究所 中国科学院藏药研究重点实验室 西宁 810008)
}

\begin{abstract}
摘要 $N$-取代-1,2,3-三氮唑是一类重要的含氮杂环化合物, 在药物化学、合成化学及材料等领域都具有广泛的应用价 值. 因此, $N$-取代-1,2,3-三氮唑的构建方法备受人们的关注. 归纳总结了近年来 $N$-取代-1,2,3-三氮唑的合成研究进展, 主要介绍了以叠氮化合物、腙、 $\mathrm{TsNHNH}_{2}$ 和重氮为氮源以及 $\mathrm{NH}-1,2,3$-三氮唑为前体合成 $N$-取代-1,2,3-三氮唑化合物 的合成路线及其反应机理，并对该领域未来的发展进行了展望.
\end{abstract}

关键词 $N$-取代-1,2,3-三氮唑; 叠氮化合物; 腙; $\mathrm{TsNHNH}_{2}$; 重氮; $\mathrm{NH}-1,2,3$-三氮唑

\section{Recent Progress in the Synthesis of $N$-Substituted-1,2,3-triazoles}

\author{
Liu, Qishun ${ }^{a} \quad$ Lü, Yufen ${ }^{a} \quad$ Bao, Pengli*,a Yue, Huilan ${ }^{*, b} \quad$ Wei, Wei ${ }^{*, a, b}$ \\ ( ${ }^{a}$ School of Chemistry and Chemical Engineering, Qufu Normal University, Qufu, Shandong 273165) \\ $\left({ }^{b}\right.$ Key Laboratory of Tibetan Medicine Research, Northwest Institute of Plateau Biology, \\ Chinese Academy of Sciences, Xining 810008)
}

\begin{abstract}
N$-Substituted-1,2,3-triazoles are an important class of nitrogen-containing hetrocyclic compounds, which exhibited wide applications in various fields such as medicinal chemistry, synthetic chemistry and materials. Therefore, their synthetic methods have attracted great attention of chemists. Herein, the recent research progress in the synthesis of $N$-substituted1,2,3-triazoles is summarized. The synthetic routes and reaction mechanisms from raw materials such as azide compounds, diazo compounds, $\mathrm{TsNHNH}_{2}$, hydrazones and $\mathrm{NH}-1,2,3$-triazoles are introduced and reviewed, respectively. Finally, the future development of this field is also prospected.

Keywords $N$-substituted-1,2,3-triazole; azide compound; hydrazone; $\mathrm{TsNHNH}_{2}$; diazo compound; $\mathrm{NH}-1,2,3$-triazole
\end{abstract}

$N$-取代-1,2,3-三氮唑是一类重要的含氮杂环化合 物，其在医药、农药、合成化学及材料等领域发挥着重 要作用. 含有该结构骨架的化合物具有广泛的生物活 性, 如消毒杀菌 ${ }^{[1]}$ 、抗癌 ${ }^{[2]}$ 、促进作物生长 ${ }^{[3]}$ 和缓蚀活 性 ${ }^{[4]} . N$-取代-1,2,3-三氮唑还可以用作染料 ${ }^{[5]}$ 、金属骨 架 ${ }^{[6]}$ 和化学探针 ${ }^{[7]}$ 等. 鉴于 $N$-取代-1,2,3-三氮唑的重要 性, 科研工作者一直致力于开发高效的合成路线构建 $N$-取代-1,2,3-三氮唑. 有机叠氮与炔烃的环加成 Click 反应 ${ }^{[8]}$ 是传统构建 $N^{1}$-取代-1,2,3-三氮唑的方法, 前人已 对其合成方法做了综述报道, 本文不做过多叙述. 主要 总结了近年来新发展的其它一些合成 $N^{1}$-和 $N^{2}$-取代1,2,3-三氮唑化合物的方法, 主要包括以叠氮化合物(叠 氮化钠、叠氮三甲基硅烷、烷基/芳基叠氮)、腙、磺酰
肼和重氮为氮源以及 $\mathrm{NH}-1,2,3$-三氮唑为前体合成 $N^{1}$-和 $N^{2}$-取代-1,2,3-三氮唑化合物的策略. 结合近年来国内外 课题组在 $N$-取代-1,2,3-三氮唑合成研究领域的报道, 本 文对其制备方法的反应类型和机理进行了分类探讨和 归纳总结，期望对未来发展 $N$-取代-1,2,3-三氮唑的制备 方法起到一定的促进作用.

\section{1 叠氮化物为氮源构建 $N$-取代-1,2,3-三氮唑}

\section{1 叠氮化钠为氮源}

叠氮化钠有剧毒, 所以直接采用叠氮化钠来构建 $N$-取代-1,2,3-三氮唑的方法相对较少. 2008 年, Fokin 课 题组 ${ }^{[9]}$ 报道了一类炔烃、叠氮化钠和甲醛三组分反应高 效构建 $N^{2}$-着弪甲基-1,2,3-三氮唑的方法(Scheme 1). 该方

\footnotetext{
* Corresponding authors. E-mail: weiweiqfnu@163.com; hlyue@nwipb.cas.cn; baopengli1992@163.com Received August 24, 2020; revised September 28, 2020; published online October 13, 2020.

Project supported by the Youth Innovation and Technology Project of Shandong Province (No. 2019KJC021), the Natural Science Foundation of Shandong Province (No. ZR2018MB009) and the International Cooperation Project of Qinghai Province (No. 2018-HZ-806).

山东省高校青创科技计划(No. 2019KJC021)、国家自然科学基金(No. ZR2018MB009)、青海省国际合作专项(No. 2018-HZ-806)资助项目.
} 
法采用便宜的硫酸铜为催化剂, 加入等物质的量的乙酸 为添加剂, 以 1,4-二氧六环为溶剂, 室温下以中等至良 好的收率(67\% 95\%)得到相应的目标产物. 该反应可 以高效构建带不同取代基的 $N^{1}$-和 $N^{2}$-羟甲基取代-1,2,3三氮唑(Scheme 1, a), 具有操作简单及条件温和的优点. $N^{2}$-羟甲基三氮唑和氯化亚砜反应可得到 $N^{2}$-氯甲基取代 - 1,2,3-三氮唑, 其进一步在二甲基亚砜(DMSO)溶剂中 与叠氮化钠反应得到 $N^{2}$-叠氮甲基-1,2,3-三氮唑. 最后, 进一步进行 click 反应得到双 1,2,3-三氮唑产物(Scheme $1, \mathrm{~b}, \mathrm{c})$.
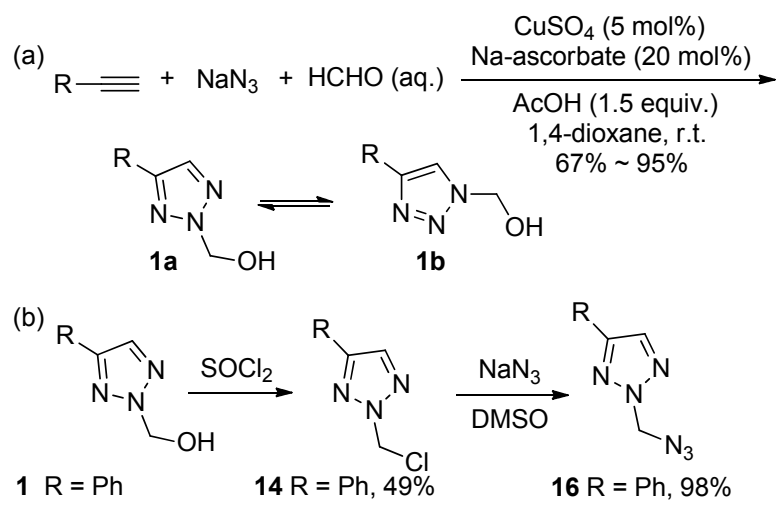

$2 \mathrm{R}=\operatorname{Phth}\left(\mathrm{CH}_{2}\right)_{2} \quad 15 \mathrm{R}=\mathrm{Phth}\left(\mathrm{CH}_{2}\right)_{2}, 41 \% \quad 17 \mathrm{R}=\mathrm{Phth}\left(\mathrm{CH}_{2}\right)_{2} 99 \%$

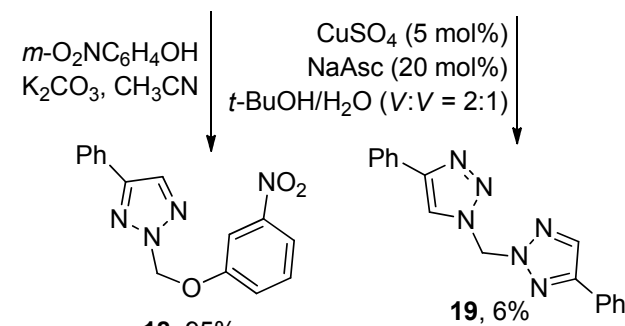

(c)
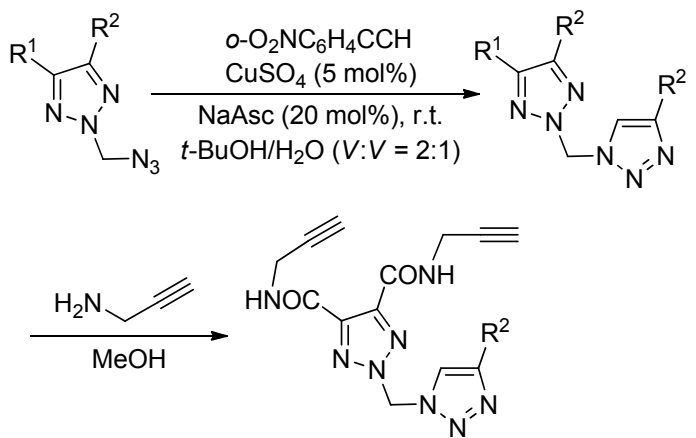

图式 1 炔烃、叠氮化钠和甲醛反应构建 $N$-取代-1,2,3-三氮唑 Scheme 1 Reaction of alkyne, sodium azide and formaldehyde to construct $N$-substituted-1,2,3-triazoles

2012 年, 陈保华课题组 ${ }^{[10]}$ 报道了氧化亚铜介导下 查尔酮、叠氮化钠和卤代芳烃三组分 “一锅法” 合成 $N^{2}$-芳基取代-1,2,3-三氮唑的方法. 该反应可以选择性地 以 $98 \%$ 的收率获得 $N^{2}$-芳基取代-1,2,3-三氮唑(Scheme 2, a). 机理研究表明氧化亚铜不仅作为氧化剂, 还作为引 发剂来促进反应进行. 反应中氮负离子中间体与卤代芳
烃进行芳基化反应得到相应的产物(Scheme 2, b).

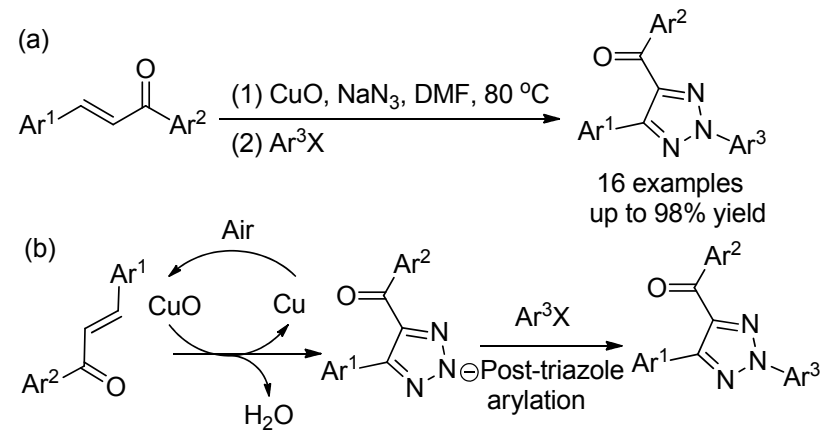

图式 2 查尔酮、叠氮化钠和卤代芳烃三组分反应构建 $N^{2}$-取 代-1,2,3-三氮唑

Scheme 2 Reaction of chalcone, sodium azide and aryl halide to construct $N^{2}$-substituted-1,2,3-triazoles

\section{2 叠氮三甲基硅烷为氮源}

叠氮三甲基硅烷作为一类重要氮源常用于构建多 种含氮化合物. 2003 年, Yamamoto 课题组 ${ }^{[11]}$ 报道了基于 炔烃、叠氮三甲基硅烷和烯丙基酯三组分环加成反应构 建 $N^{2}$-烯丙基取代-1,2,3-三氮唑的方法(Scheme 3). 该方 法以钯/铜盐为双金属催化剂，以乙酸乙酯为溶剂，在 $100{ }^{\circ} \mathrm{C}$ 反应条件下以中等至较好收率得到相应的 $N^{2}$-烯 丙基取代-1,2,3-三氮唑.

$$
\mathrm{R}=\mathrm{H}+\mathrm{OCO}_{2} \mathrm{Me} \frac{\mathrm{TMSN}_{3}+\underset{\mathrm{Pd}(\mathrm{OPh})_{3}(2 \mathrm{~mol} \%)}{\mathrm{PuCl}(\mathrm{PPh})_{3}(10 \mathrm{~mol} \%)}}{\mathrm{AcOEt}, 100^{\circ} \mathrm{C}}
$$

图式 3 炔烃、叠氮化钠和烯丙基酯反应构建 $N^{2}$-取代-1,2,3三氮唑

Scheme 3 Reaction of alkyne, $\mathrm{TMSN}_{3}$ and allyl ester to construct $N$-substituted -1,2,3-triazoles

其反应机理如 Scheme 4 所示: 该反应可能经历 $\operatorname{Pd}(0)-\mathrm{Cu}(\mathrm{I})$ 双金属催化循环过程. 首先, 碳酸烯丙酯和 $\mathrm{TMSN}_{3}$ 反应，通过 $\mathrm{Pd}(0)$ 催化放出 $\mathrm{CO}_{2}$ 和 TMSOMe，同 时生成 $\pi$-烯丙基钯叠氮化络合物 $\mathbf{A}$. 炔烃 $\mathbf{1}$ 和 $\mathrm{CuClL}_{n}$ 反应形成乙炔铜 $\mathbf{B}$, 并通过末端反应生成 $\mathrm{HCl}$. 接下来, 叠氮化配合物 $\mathbf{A}$ 和乙炔铜 $\mathbf{B}$ 进一步形成中间体 $\mathbf{C}$, 使得 $[3+2]$ 环合反应顺利进行. 中间体 $\mathbf{C}$ 通过钯配合物 $\mathbf{D}$ 的 干预与中间体 $\mathbf{E}$ 处于平衡状态. 最后，通过质子分解得 到 2-烯丙基-1,2,3-三氮唑 2.

2016 年, Tiwari 课题组 ${ }^{[12]}$ 报道了一种炔烃、叠氮三 甲基硅烷和二甲基亚砜三组分反应构建 $N^{1}$-甲硫甲基1,2,3-三氮唑的方法(Scheme 5). 该反应以双金属 $\mathrm{Cu}^{0}$ \% $\mathrm{Fe}_{3} \mathrm{O}_{4}$ 为催化剂, 以二甲基亚砜为反应溶剂, 在 $80{ }^{\circ} \mathrm{C}$ 条 


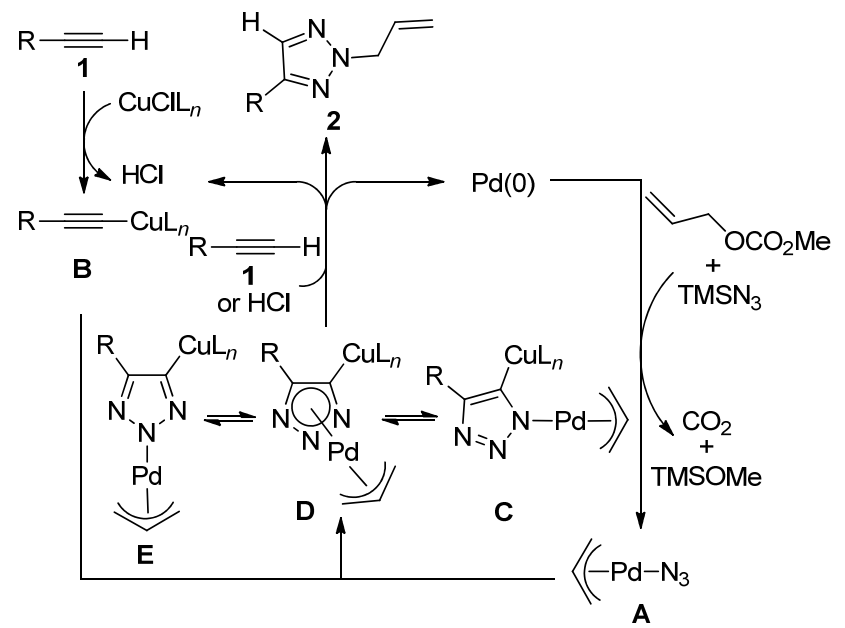

图式 4 炔烃、叠氮化钠和烯丙基酯反应机理

Scheme 4 Proposed mechanism for the reaction of alkyne, $\mathrm{TMSN}_{3}$ and allyl ester

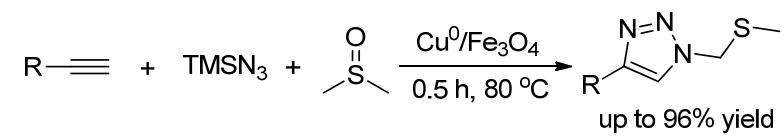

图式 5 炔烃、 $\mathrm{TMSN}_{3}$ 和二甲基亚砜反应构建 $N^{1}$-取代-1,2,3三氮唑

Scheme 5 Reaction of alkyne, $\mathrm{TMSN}_{3}$ and dimethyl sulfoxide to construct $N^{1}$-substituted-1,2,3-triazoles

件下高效合成 $N^{1}$-甲硫基甲基-1,2,3-三氮唑. 焦宁课题 组 ${ }^{[13]}$ 采用烯烃/炔烃、磷酰基叠氮和二甲基亚砜为原料 在 $\mathrm{Cu}(\mathrm{acac})_{2}$ 催化下也完成了 $N^{1}$-甲硫甲基-1,2,3-三氮唑 的构建. 该反应采用叠氮三甲基硅烷为氮源, 可以有效 避免预先制备磷酰基叠氮，为 $N^{1}$-甲硫甲基-1,2,3-三氮 唑提供了一种简单、高效的合成路线.

底物扩展研究发现，该反应中带不同基团如对丙 基、对戊基和间三氟甲基的芳炔在最优的反应条件下可 以高产率地得到 $N^{1}$-甲硫基甲基取代-1,2,3-三氮唑 (Scheme 6). 各种杂芳烃包括噻吩基、2-吡啶基和吡咯衍 生物也可以很好地兼容该反应. 此外, 多环芳烃炔烃如 9-乙炔基菲在最优的条件下以 $89 \%$ 的收率得到产物 $3 \mathbf{n}$. 脂族炔烃也适用于该反应, 相应的产物得到中等的收 率. 该反应底物范围广泛, 为合成 $N^{1}$-甲硫基甲基-1,2,3三氮唑提供了一个具有吸引力的合成方法.

其反应机理如 Scheme 7 所示: 首先 DMSO 与 $\mathrm{TMSN}_{3}$ 反应生成中间体 $\mathbf{A}$. 中间体 $\mathbf{A}$ 失去质子生成硫鎓 离子 $\mathbf{B}$, 经过叠氮负离子的亲核取代得到中间体 $\mathbf{C}$. 然 后, 中间体 $\mathbf{C}$ 与炔铜发生 Click 反应生成中间体 $\mathbf{D}$, 再 经过还原消除铜物种得到目标产物.

2019 年, 张敏课题组 ${ }^{[14]}$ 报道了一种硫酸银催化下 炔烃、 $\mathrm{TMSN}_{3}$ 和 1,3-二酮三组分反应构建 $N^{1}$-烯基-1,2,3三氮唑的方法. 该反应以 $\mathrm{NaHCO}_{3}$ 为碱, 在 $70{ }^{\circ} \mathrm{C}$ 反应<smiles>CCCc1ccc(-c2cn(CC)nn2)cc1</smiles><smiles>CCn1cc(C(C)C)nn1</smiles>

3n, $89 \%$

$3 p, 66 \%$

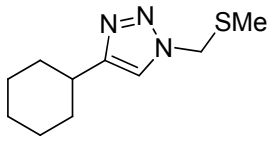

3s, $63 \%$

图式 6 部分 $N^{1}$-取代-1,2,3-三氮唑产物

Scheme 6 Partial $N^{1}$-substituted-1,2,3-triazoles

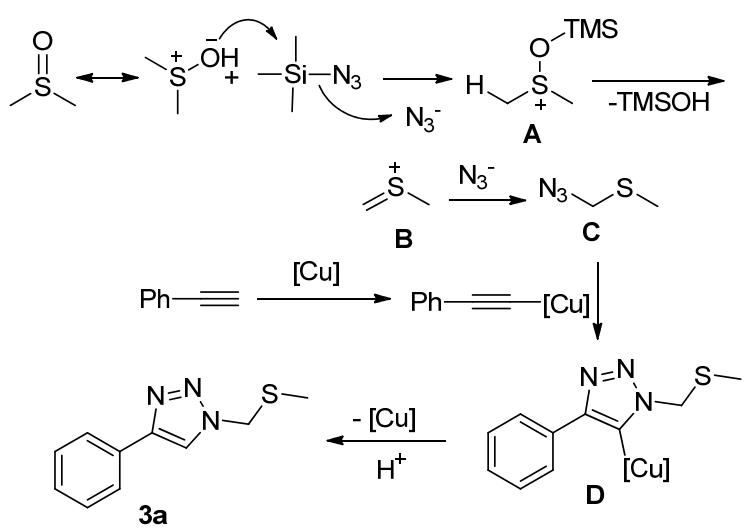

图式 7 构建 $N^{1}$-取代-1,2,3-三氮唑的反应机理 Scheme 7 Proposed mechanism for the construction of $N^{1}$ substituted-1,2,3-triazoles

条件下得到 $N^{1}$-烯基-1,2,3-三氮唑(Scheme 8). 该合成方 法操作简单, 底物官能团相容性好, 为 $N^{1}$-烯基-1,2,3-三 氮唑提供了一种有效的合成方法.

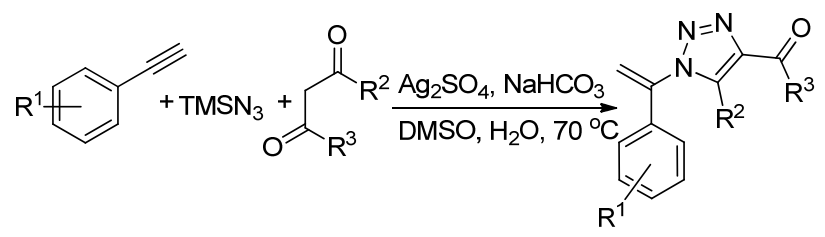

图式 8 炔烃、 $\mathrm{TMSN}_{3}$ 和 1,3-二酮反应构建 $N^{1}$-烯基取代-1,2,3三氮唑

Scheme 8 Reaction of alkyne, $\mathrm{TMSN}_{3}$ and 1,3-dicarbonyl to construct $N^{1}$-vinyl-1,2,3-triazoles

反应机理如 Scheme 9 所示: 首先, $\mathrm{Ag}_{2} \mathrm{SO}_{4}$ 与 $\mathrm{TMSN}_{3}$ 反应生成 $\mathrm{AgN}_{3}$ 以及 $(\mathrm{TMS})_{2} \mathrm{SO}_{4}$. 然后, $\mathrm{AgN}_{3}$ 对 苯乙炔进行加成反应得到叠氮乙烯基银 $\mathbf{A}$. 然后, 叠氮 乙烯基银 $\mathbf{A}$ 与 $\mathrm{H}_{2} \mathrm{O}$ 进行还原脱金属反应形成烯基叠氮 
中间体 B. 碱性条件下, 中间体 $\mathbf{B}$ 与 1,3-二酮进行 1,3偶极环加成反应生成加合物 $\mathbf{C}$. 化合物 $\mathbf{C}$ 经过 1,3-氢迁 移和重排反应得到中间体 $\mathbf{E}$. 最后, 中间体 $\mathbf{E}$ 脱去一分 子水生成所需的产物 $\mathbf{4 a b}$.

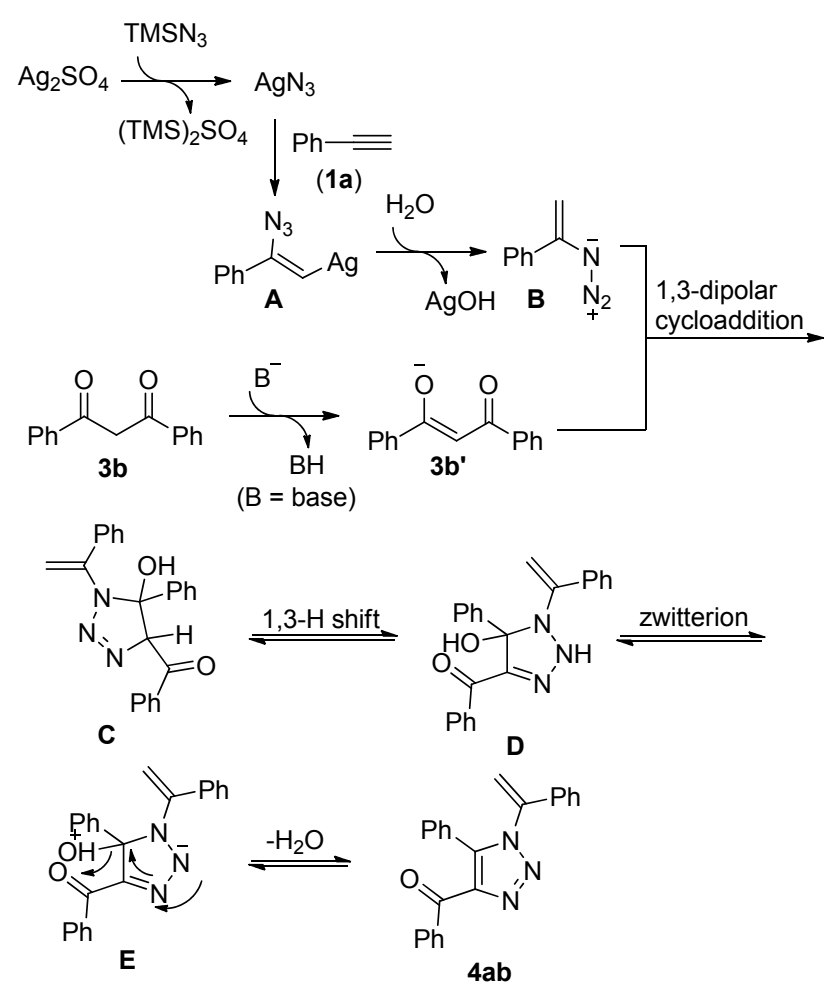

图式 9 构建 $N^{1}$-烯基取代-1,2,3-三氮唑的反应机理

Scheme 9 Proposed mechanism for the construction of $N^{1}$ vinyl-1,2,3-triazoles

氧烷基结构单元常作为关键骨架存在于多种具有 生物活性的药物分子和天然产物中. 近年来有机合成工 作者一直尝试将氧烷基团引入到 1,2,3-三氮唑中来增强 其生物活性. 2019 年, 魏伟课题组 ${ }^{[15]}$ 报道了一种炔烃、 叠氮三甲基硅烷和醚三组分串联反应选择性构建 $N^{1}$-和 $N^{2}$-烷氧基-1,2,3-三氮唑的方法. 该方法以氯化亚铜为催 化剂, 以过氧化叔丁醇为氧化剂, 以醚为溶剂和反应物, 在 $80{ }^{\circ} \mathrm{C}$ 反应条件下以较高的收率得到相应的目标产 物. 值得注意的是, 该方法可以通过改变铜盐的用量来 选择性调控 $N^{1}$-或 $N^{2}$-氧烷基-1,2,3-三氮唑的合成. 当氯 化亚铜的量为 $5 \mathrm{~mol} \%$ 时, 主要得到 $N^{1}$-氧烷基-1,2,3-三 氮唑, 当氯化亚铜的用量增加到 $20 \mathrm{~mol} \%$ 时, 主要得到 $N^{2}$-氧烷基-1,2,3-三氮唑(Scheme 10).

该反应可能的机理如 Scheme 11 所示, $N^{1}$-氧烷基 1,2,3-三氮唑合成一种可能的途径 $\mathrm{A}$ 是: 铜催化过氧化 叔丁基醇( TBHP)分解产生自由基 $t$ - $\mathrm{BuOO} ・$ 和 $t$ - $\mathrm{BuO}$, 它 们从四氢呋喃(THF) (3a) 的 $\alpha-\mathrm{CH}$ 中夺去一个氢原子形 成 $\alpha$-氧烷基自由基 6a. 然后, $\alpha$-氧烷基自由基 $6 \mathrm{a}$ 进一步 被氧化产生 $\alpha$-氧烷基阳离子 $7 \mathbf{a}$. 接着, $\mathrm{TMSN}_{3}$ 对 $\mathbf{7 a}$ 进

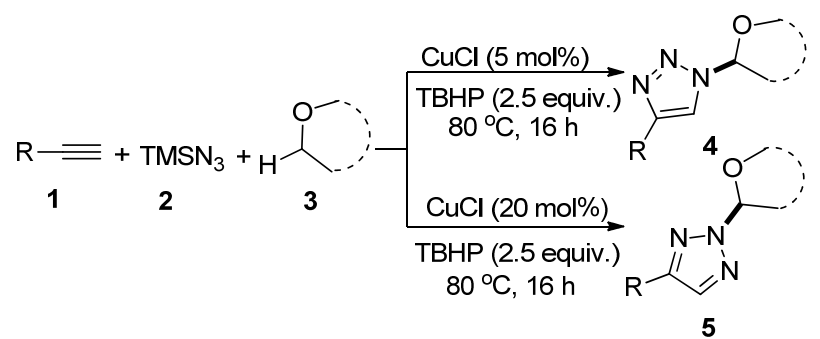

图式 10 炔烃、 $\mathrm{TMSN}_{3}$ 和烷氧基醚反应选择性构建 $N^{1}$-和 $N^{2}$ 氧烷基-1,2,3-三氮唑

Scheme 10 Reaction of alkyne, $\mathrm{TMSN}_{3}$ and ether to selectively construct $N^{1}$ - and $N^{2}$-oxyalkylated-1,2,3-triazoles

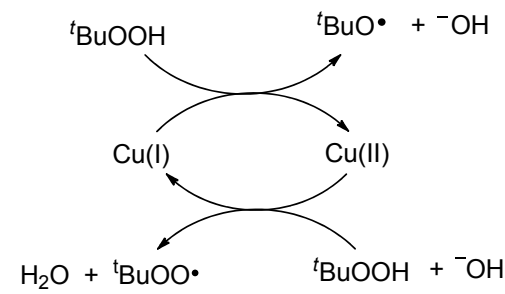

Pathway A (4a):
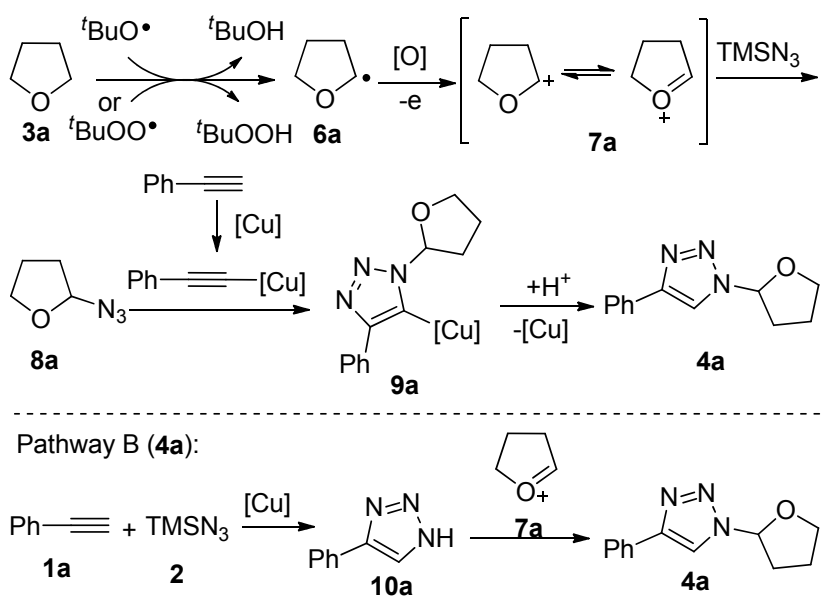

Pathway (5a):
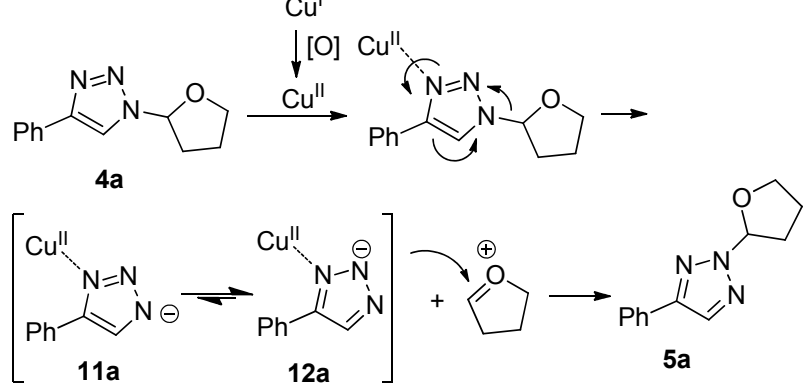

图式 11 选择性构建 $N^{1}$-和 $N^{2}$-氧烷基-1,2,3-三氮唑的反应机 理

Scheme 11 Proposed mechanism for the selective construction of $N^{1}$ - and $N^{2}$-oxyalkylated-1,2,3-triazoles

行亲核反应产生 $\alpha$-叠氮醚 $8 \mathrm{a}, 8 \mathrm{a}$ 与苯乙炔 $1 \mathrm{a}$ 进行反应 得到所需的产物 $4 a$. 另一个可能的途径 $B$ 是苯乙炔 $1 a$ 
首先与 $\mathrm{TMSN}_{3}$ 反应, 生成 4-苯基- $1 H-1,2,3$-三氮唑 10a. 后者进一步与 $\alpha$-氧烷基阳离子 7a 反应得到产物 $4 \mathbf{a} . N^{1}$ 氧烷基-1,2,3-三氮唑产物 $\mathbf{5 a}$ 通过铜盐介导 $N^{1}$-氧烷基 -1,2,3-三氮唑中醚基团 1,2-转移过程生成.

同一年, 魏伟课题组 ${ }^{[16]}$ 又开发了利用炔酸、 $\mathrm{TMSN}_{3}$ 和醚三组分串联反应选择性构建 $N^{1}$-和 $N^{2}$-氧烷基取代1,2,3-三氮唑的方法(Scheme 12). 该反应同样可以通过 控制催化剂 $\mathrm{CuCl}_{2}$ 的用量来控制 $N^{1}$-和 $N^{2}$-氧烷基-1,2,3三氮唑产物的生成. 当 $\mathrm{CuCl}_{2}$ 用量为 $5 \mathrm{~mol} \%$ 时, 得到 $N^{1}$-氧烷基-1,2,3-三氮唑. 当 $\mathrm{CuCl}_{2}$ 的量增加到 $20 \mathrm{~mol} \%$ 时, 生成 $N^{2}$-氧烷基-1,2,3-三氮唑. 炔烃易挥发, 易燃易 爆, 沸点低, 不稳定且不易于保存, 挥发到空气中有刺 激性气味, 故而不利于工业化生产. 该反应使用固体炔 酸代替炔烃, 反应操作简便、高效, 在有机合成和药物 化学中具有潜在的应用价值.

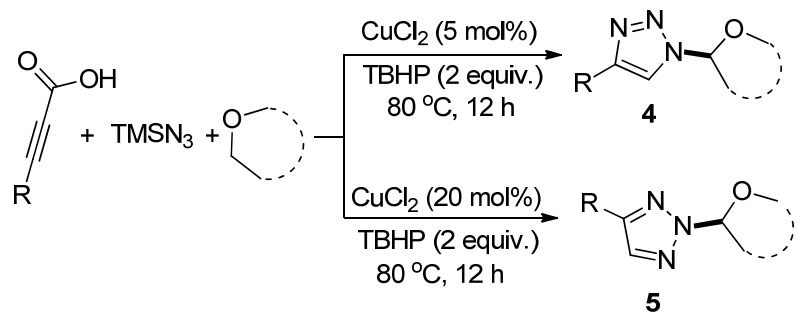

图式 12 铜催化炔酸、 $\mathrm{TMSN}_{3}$ 和烷氧基醚三组分反应构建 $N^{1}-$ 和 $N^{2}$-氧烷基-1,2,3-三氮唑

Scheme 12 Copper catalyzed three-component reaction of alkynyl carboxylic acid, $\mathrm{TMSN}_{3}$ and ether to construct $N^{1}$ - and $N^{2}$-oxyalkylated-1,2,3-triazoles

该反应机理与铜催化炔烃、叠氮三甲基硅烷和醚三 组份反应选择性构建 $N^{1}$-和 $N^{2}$-烷氧基取代-1,2,3-三氮唑 的路径类似, 区别之处在于炔酸与铜盐需进行脱羧反应 生成炔铜中间体，然后进行后续的环化反应.

\section{3 以烷基/芳基叠氮化物为氮源}

烷基/芳基叠氮常被用作氮源来合成多取代 1,2,3-三 氮唑化合物. 2019 年, Virant 课题组 ${ }^{[17]}$ 报道了一种高效的 炔烃、叠氮化物与芳基碘鎓盐在铜盐催化条件下合成 1,3,4-三芳基取代-1,2,3-三氮唑盐的方法. 该反应操作简 单, 底物适用范围广, 为多种具有生物活性的 $1,3,4$-三 芳基-1,2,3-三氮唑盐提供了一种有效的合成方法 (Scheme 13).

2018 年, 潘英明课题组 ${ }^{[18]}$ 报道了一种铜催化炔酸、 二硒醚和叠氮化物三组分串联反应构建 $N$-烷基-5-硒代 $1,2,3$-三氮唑化合物的方法. 该反应以醋酸铜作为催化 剂，碳酸钾为还原剂，在 $120{ }^{\circ} \mathrm{C}$ 条件下反应可高效得到 多种具有抗癌活性的 $N$-烷基-5-硒代-1,2,3-三氮唑化合 物. 该反应具有操作简便、高区域选择性以及与空气相 容性好的特征. 合成的多种 $N$-烷基-5-硒代 1,2,3-三氮唑

$$
\mathrm{R}^{1}-\mathrm{N}_{3}+\mathrm{R}^{2}=+\mathrm{Ar}-\mathrm{+}-\mathrm{R} \frac{\left[\mathrm{Cu}\left(\mathrm{PPh}_{3}\right)_{3} \mathrm{Br}\right]}{\text { stepwise or one-pot }} \mathrm{R}^{2} \underset{\substack{\mathrm{N}^{\mathrm{N}}-\mathrm{N} \\ \mathrm{Ar}}}{\overbrace{1}^{\mathrm{N}-\mathrm{R}^{1}}}
$$

图式 13 铜催化构建 1,3,4-三芳基-1,2,3-三氮唑盐 Scheme 13 Copper catalyzed synthesis of 1,3,4-triaryl-1,2,3triazolium salts

化合物如 4f, $4 \mathrm{~h}$ 和 $4 \mathrm{p}$ 在体外表现出有效的抗癌活性 (Scheme 14).

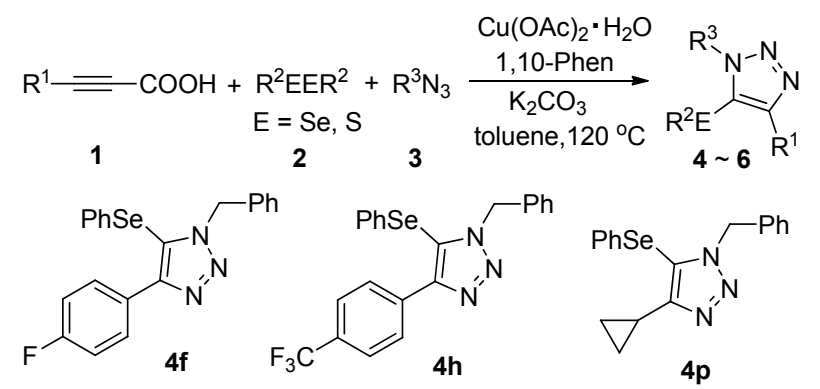

图式 14 铜催化炔酸、叠氮化物和二硒醚三组分反应构建 $N$ 烷基-5-硒代-1,2,3-三氮唑

Scheme 14 Copper catalyzed three-component reaction of acetylenic acid, azide and diselenide for the construction of $\mathrm{N}$ alkyl-5-arylselanyl-1,2,3-triazoles

其反应机理如 Scheme 15 所示: 首先, 将 1,10-Phen 与 $\mathrm{Cu}(\mathrm{OAc})_{2} \cdot \mathrm{H}_{2} \mathrm{O}$ 配位形成活性 $\mathrm{Cu}(\mathrm{II})$ 中间体 $\mathbf{A}$, 然后与 炔酸 $1 \mathrm{a}$ 反应生成铜(II)中间体 B. B 进一步释放出一个分 子 $\mathrm{CO}_{2}$ 生成中间体 C. $\mathbf{C}$ 与二苯基二硒醚(2a)反应生成中 间体 D, D 发生还原消除反应生成苯基(苯基乙炔基)-硒 烷(7)和铜(I)化合物 E. E 与苯基(苯基乙炔基)硒烷(7)和 叠氮化物 3a 生成中间体 F. 然后, 其进行氧化环加成反 应形成中间体 $\mathbf{G}$. 接着, $\mathbf{G}$ 发生还原消除反应得到所需 的产物 $4 a$ 和铜(I)化合物 $\mathbf{E}$. 最后，在空气条件下将 $\mathbf{E}$ 转 化为 $\mathbf{A}$ 完成反应循环.

2016 年, Dehaen 课题组 ${ }^{[19]}$ 报道了一种以炔丙基胺、 酮和对硝基苯基叠氮为原料构建 $N^{1}$-取代-1,2,3-三氮唑 化合物的方法(Scheme 16, a). 该反应使用等物质的量的 醋酸锌为催化剂，以 $N, N$ 二甲基甲酰胺(DMF)为溶剂, 在 $60{ }^{\circ} \mathrm{C}$ 条件下可高效得到相应的 $N^{1}$-取代-1,2,3-三氮 唑. 值得注意的是, 苯乙酮作为反应物时, 当温度增加 到 $100{ }^{\circ} \mathrm{C}$ 时无需醋酸锌作为催化剂, 反应即可得到双 三氮唑衍生物(Scheme 16, b).

其反应机理描述如 Scheme 17 所示: 炔丙基胺在路 易斯酸介导条件下和酮反应生成亚胺, 其进一步异构为 烯胺，接着烯胺与叠氮化物进行环加成反应形成三氮唑 啉中间体. 三氮唑啉中间体通过开环反应和对硝基苯胺 反应，经历消除过程得到相应的 $N^{1}$-取代-1,2,3-三氮唑. 2015 年, 陈云峰课题组 ${ }^{[20]}$ 报道了一种铜催化硝基 


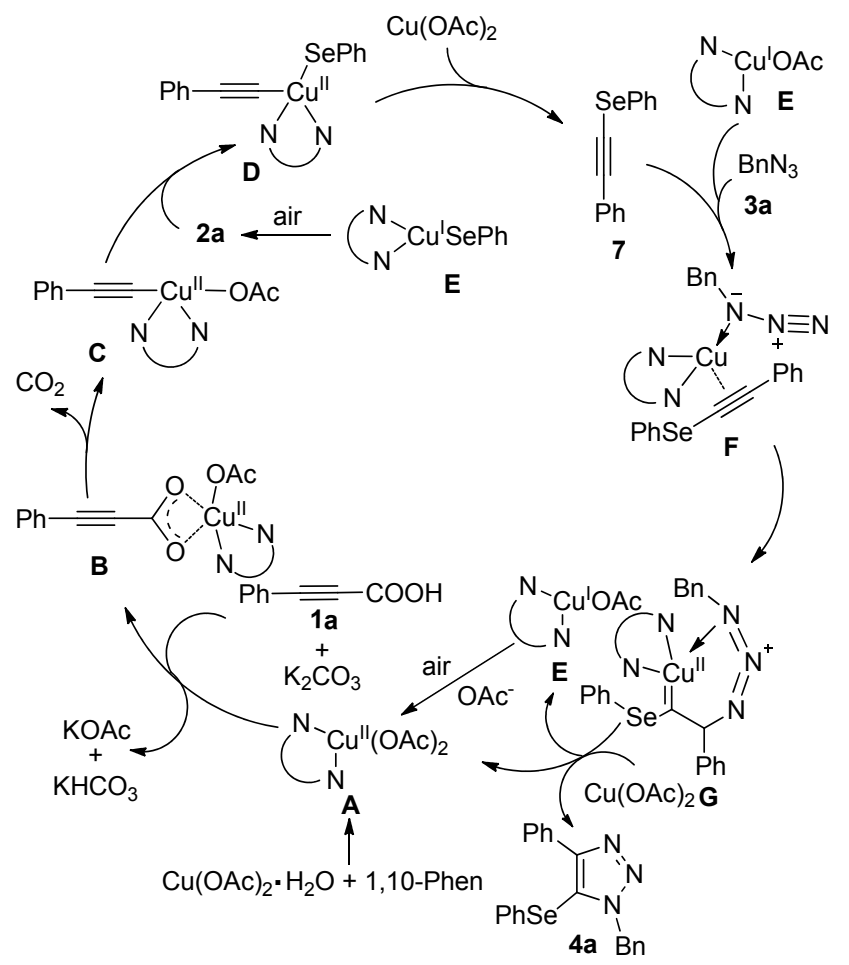

图式 15 构建 $N$-烷基-5-硒代 1,2,3-三氮唑的反应机理 Scheme 15 Mechanism for the construction of $N$-alkyl-5arylselanyl 1,2,3-triazoles

(a)

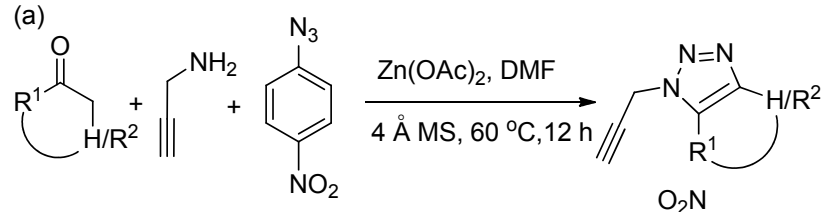

(b)

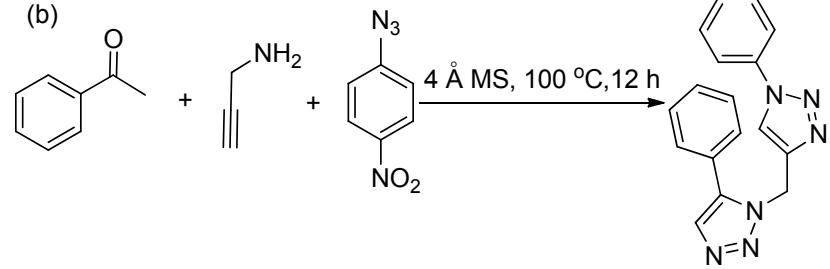

图式 16 炔丙基胺、酮和对硝基苯基叠氮三组分反应构建 $N^{1}$ 取代-1,2,3-三氮唑

Scheme 16 Three-component reaction of propargylamine, ketone and $p$-nitrophenyl azide to construct $N^{1}$-substituted-1,2,3triazoles

烯烃和有机叠氮的环加成反应构建 $N^{1}$-烷/芳基 4-硝基1,2,3-三氮唑化合物的方法. 该反应在以 $\mathrm{Cu}(\mathrm{OTf})_{2}(5$ $\mathrm{mol} \%)$ 作为催化剂的条件下, 以 $\mathrm{DMF} / \mathrm{AcOH}(V: V=$ $4: 1)$ 为溶剂, 在 $110{ }^{\circ} \mathrm{C}$ 下高收率得到相应的 $N$-烷/芳 基-4-硝基-1,2,3-三氮唑化合物. 该反应操作简单，底物 适用范围广, 克服了硝基化合物与有机叠氮化物进行环 加成反应需要使用 $\mathrm{HNO}_{2}$ 的问题, 为 $N^{1}$-烷基-4-硝基1,2,3-三氮唑提供了一种有效的合成策略(Scheme 18).

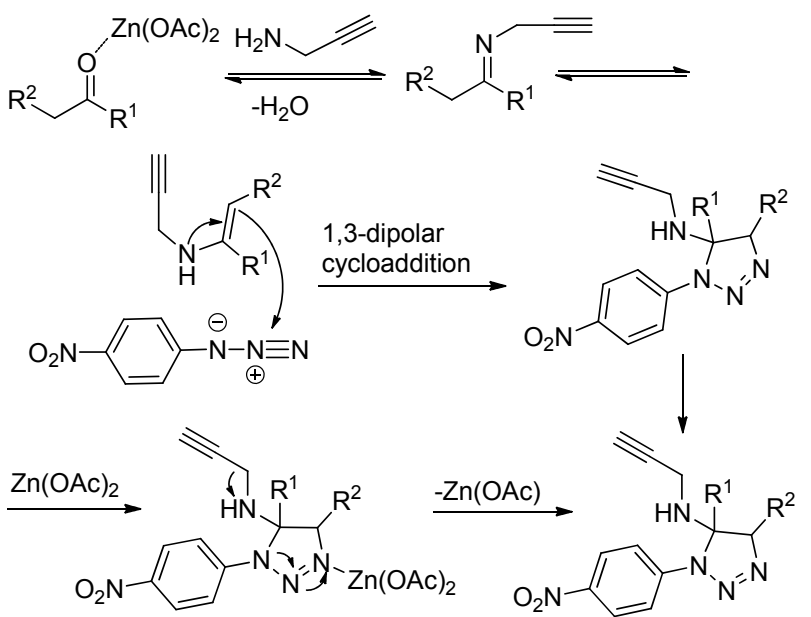<smiles>[R]c1nnn(CC#C)c1[R]</smiles>

图式 17 炔丙基胺、酮和对硝基苯基叠氮三组分反应机理 Scheme 17 Mechanism for the three-component reaction of propargylamine, ketone and $p$-nitrophenyl azide

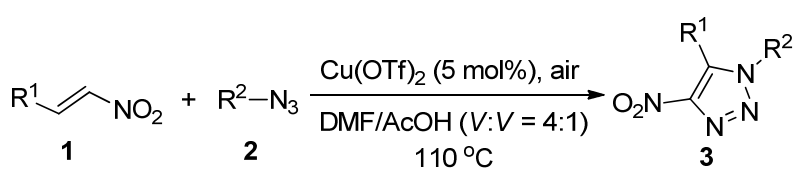

图式 18 铜催化硝基烯烃和叠氮化物反应构建 $N^{1}$-取代1,2,3-三氮唑

Scheme 18 Copper catalyzed reaction of nitroalkenes and azides to construct $N^{1}$-substituted-1,2,3-triazoles

反应机理如 Scheme 19 所示: 首先, 硝基烯烃 $\mathbf{1}$ 与 有机叠氮 2 进行区域选择性 1,3-偶极环加成反应形成三 氮唑啉中间体 I. 然后，中间体 $\mathbf{I}$ 在 $\mathrm{Cu}(\mathrm{II})$ 氧化下形成 $\mathrm{Ar}$ 基团稳定的自由基 II, 其经过单电子氧化生成阳离子中 间体 III. 该中间体失去质子形成硝基取代的 1,2,3-三氮 唑化合物 3. $\mathrm{Cu}(\mathrm{I})$ 可以在酸性条件下与氧气反应生成 $[\mathrm{Cu}(\mathrm{II})-\mathrm{O}-\mathrm{O} \cdot$ 或 $[\mathrm{Cu}(\mathrm{II})-\mathrm{O}-\mathrm{OH}]$, 然后解离为生成 $\mathrm{Cu}(\mathrm{II})$ 完成催化循环

2017 年，陈云峰课题组 ${ }^{[21]}$ 采用芳香甲基酮、 $N, N$ 二甲基甲酰胺和有机叠氮为原料，在硝酸铜和过二硫酸 钾介导下实现了三组分环加成反应构建 $N^{1}$-烷/芳基1,2,3-三氮唑化合物(Scheme 20). 在铜盐和过二硫酸钾 作用下，该反应可能经过芳香甲基酮与 $N, N$-二甲基甲酰 胺的氧化偶联反应得到中间体 $\mathbf{A}$, 其可以进一步脱掉 $N$ 甲基甲酰胺形成烯酮中间体 $\mathbf{B}$. 中间体 $\mathbf{A}$ 或 $\mathbf{B}$ 在铜催化 下与有机叠氮进行氧化环加成反应得到 $N^{1}$-烷/芳基取 代-1,2,3-三氮唑化合物. 


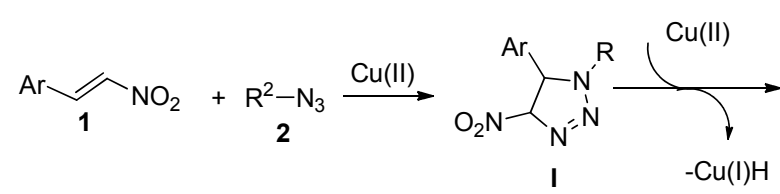<smiles>[R]N1N=NC([N+](=O)[O-])C1[Al]C[CH-]C</smiles>
$\mathrm{Cu}(\mathrm{II})$ regenerate: $\mathrm{Cu}(\mathrm{I})-\mathrm{H} \stackrel{\mathrm{O}_{2}}{\longrightarrow} \mathrm{Cu}(\mathrm{II})-\mathrm{OOH} \stackrel{\mathrm{H}^{+}}{\longrightarrow} \mathrm{Cu}(\mathrm{II})+\mathrm{H}_{2} \mathrm{O}_{2}$

图式 19 合成 $N^{1}$-取代-1,2,3-三氮唑可能的反应机理 Scheme 19 Possible reaction mechanism for the synthesis of $N^{1}$-substituted-1,2,3-triazoles

$$
\text { 至 }
$$

图式 20 铜催化芳香甲基酮、 $N, N$-二甲基甲酰胺和有机叠氮 三组分反应构建 $N^{1}$-烷/芳基取代-1,2,3-三氮唑

Scheme 20 Copper catalyzed three-component reaction of aryl methyl ketone, $\mathrm{N}, \mathrm{N}$-dimethylformamide and organic azide to construct $N^{1}$-alkyl/aryl-1,2,3-triazoles

2018 年, Kumar 课题组 ${ }^{[22]}$ 报道了一种铜催化肉桂酸 与芳基叠氮化物的脱羧反应构建 $N^{1}$-芳取代三氮唑化合 物的方法(Scheme 21). 该方法以 $\mathrm{Cu}(\mathrm{OTf})_{2}$ 为催化剂, 以 抗坏血酸/DMF 为反应溶剂, 在 $115{ }^{\circ} \mathrm{C}$ 下高效得到 1,5二取代-1,2,3-三氮唑. 作者对各种芳基取代的叠氮化合 物和肉桂酸进行了底物适应性考察, 发现各种官能基团 包括卤素、硝基、氰基等都可以适用于该反应条件.

$\mathrm{Cu}(\mathrm{II})$ 催化合成 $N^{1}$ - 芳基-1,2,3-三氮唑的机理如 Scheme 22 所示: 首先, 芳基叠氮与肉桂酸进行区域选 择性 1,3-偶极环加成反应, 形成阳离子中间体 $\mathbf{A}, \mathbf{A}$ 经过 铜迁移得到中间体 $\mathbf{B}$. 随后, $\mathbf{B}$ 失去一个质子得到 1,4,5三取代-1,2,3-三氮唑铜 D. 在酸性介质中, 铜络合物 D 易于分解提供游离的 $N^{1}$-芳基取代- 1,2,3-三氮唑. 最后, 在酸性条件下 $\mathrm{Cu}(\mathrm{I})$ 氧化生成 $\mathrm{Cu}(\mathrm{II})$, 并使 $\mathrm{Cu}(\mathrm{II})$ 物种再 次参与催化循环.

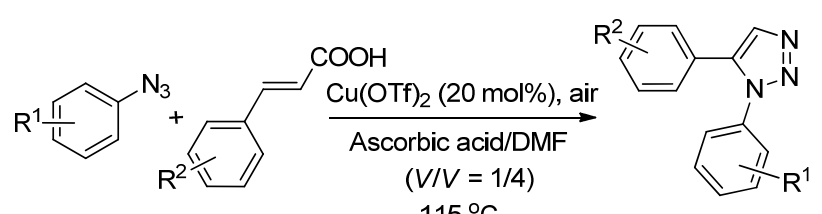

$115^{\circ} \mathrm{C}$

图式 21 铜催化芳基叠氮和肉桂酸反应构建 $N$-芳基-1,2,3-三 氮唑

Scheme 21 Copper catalyzed reaction of arylazide and cinnamic acid to construct $N$-aryl-1,2,3-triazoles

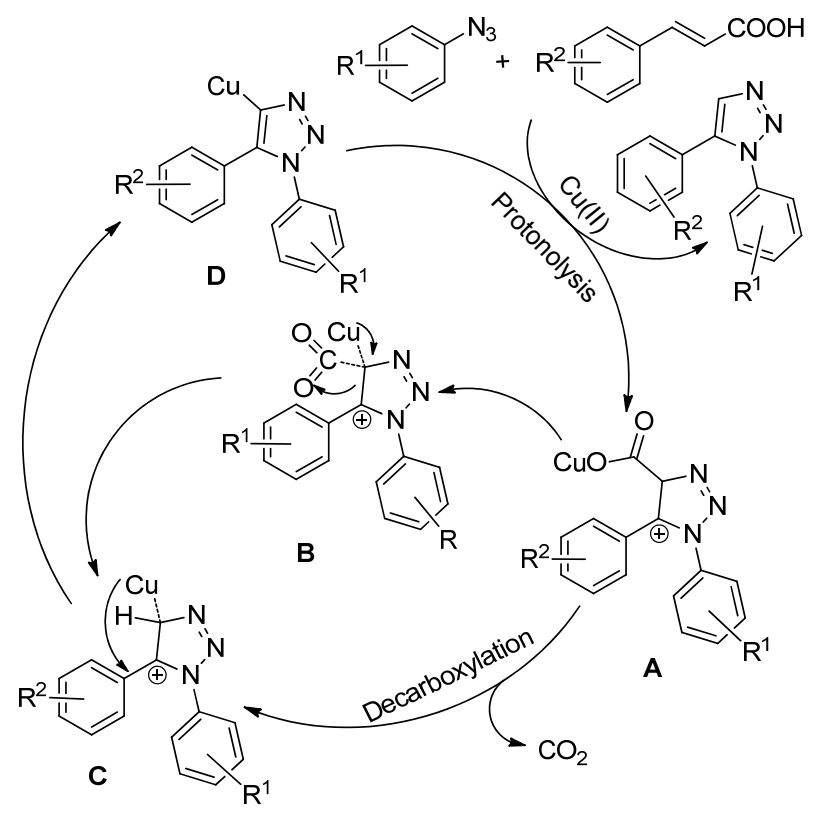

图式 22 铜催化芳基叠氮和肉桂酸反应机理

Scheme 22 Proposed mechanism for copper catalyzed reaction of arylazide and cinnamic acid

2015 年, 徐正虎课题组 ${ }^{[23]}$ 报道了钯/铜共催化炔烃、 烷基/芳基叠氮和芳基卤三组分反应构建多种类型 $N^{1}$-取 代-1,2,3-三氮唑化合物的方法. 该反应可为传统的 CuAAC click 局限于末端炔烃提供了一个解决方法 (Scheme 23).

$$
\begin{aligned}
& \mathrm{Pd}_{2}(\mathrm{dba})_{3}(1 \mathrm{~mol} \%)
\end{aligned}
$$

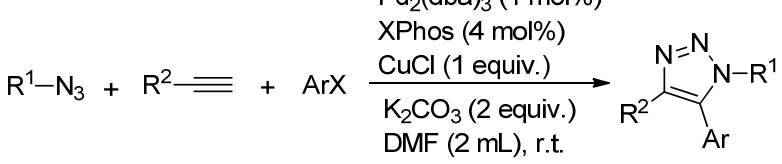

图式 23 炔烃、烷基/芳基叠氮和芳基卤三组分反应构建 $N^{1}-$ 取代-1,2,3-三氮唑

Scheme 23 Reaction of alkyne, alkyl/aryl azide and aryl halide to construct $N^{1}$-substituted-1,2,3-triazoles

2016 年, 徐正虎课题组 ${ }^{[24]}$ 开发了一种以碘化亚铜 催化炔烃、烷基叠氮和硫代磺酸酯或硒代磺酸酯构建 $N^{1}$ - 烷基-5-硫/硒/氨基-1,2,3-三氮唑化合物的方法 (Scheme 24). 该反应在非常温和的条件下进行，底物适 用范围广，各种脂肪硫醇和芳香硫酚都可以很好兼容该 
反应条件. 值得注意的是, 硒代磺酸酯也适用于该反应, 以 71\%的收率得到产物 11. 此外, 各种二级脂肪胺包括 环状和链状胺都可以较好地反应, 生成一系列 $N^{1}$-烷基5-氨基-1,2,3-三氮唑化合物(10t～10w).

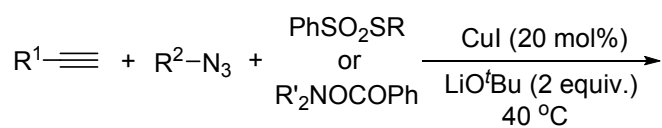

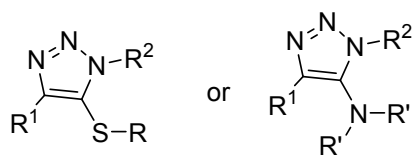
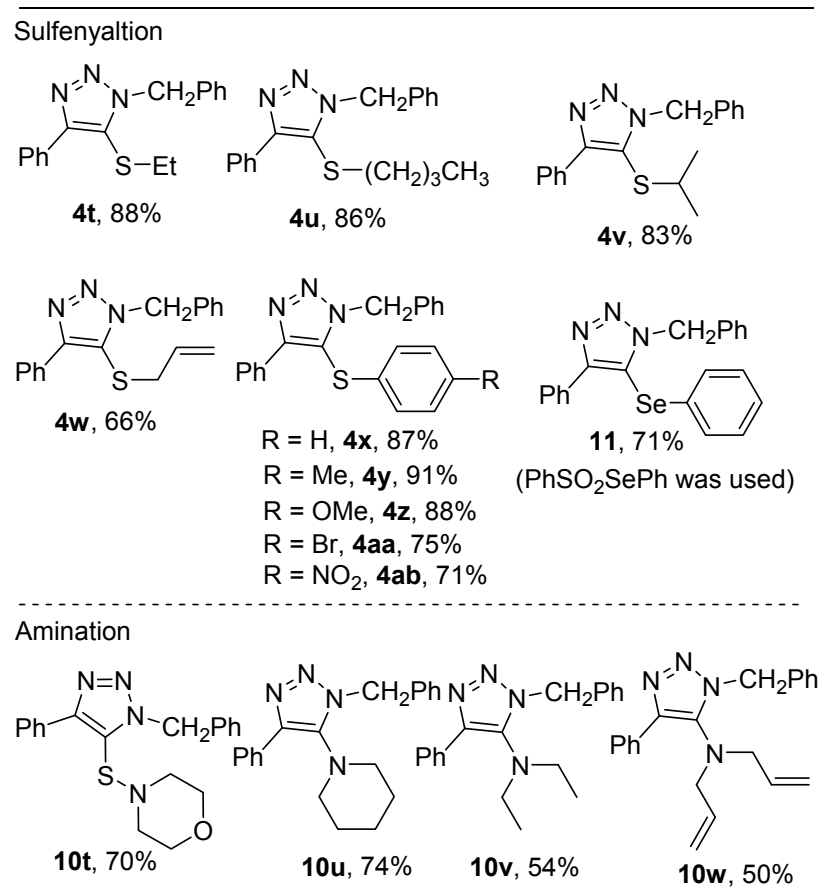

图式 24 铜催化三组分反应构建 $N$-烷基-5-硫/硒代/氨基1,2,3-三氮唑

Scheme 24 Copper catalyzed three-component reaction to construct $N$-alkyl-5-thio/selenyl/amino-1,2,3-triazoles

该反应可能的机理如 Scheme 25 所示: 首先, 炔烃 与碘化亚铜反应生成的炔铜 $\left(\mathbf{M}^{0}\right)$ 与烷基叠氮 2 进行环加 成反应生成铜盐-三氮唑 $\mathbf{M}^{\mathbf{1}}$. 该中间体可能通过氧化加 成和还原消除历程与杂原子亲电子体 E-LG 反应形成产 物 4. $\mathrm{Cu}-\mathrm{LG}$ 在碱的存在下与炔烃反应形成乙炔铜(I) $\left(\mathbf{M}^{0}\right)$, 从而完成了催化循环的过程.

随后, 徐正虎课题组 ${ }^{[25]}$ 又连续开发了两种氯化亚 铜催化的有机叠氮和炔烃分别与炔基溴和叔丁基对甲 苯磺酰基过二硫酯的三组分反应构建 $N^{1}$-烷基-5-炔 基 -1,2,3-三氮唑和 $N^{1}$-烷基-5-二硫-1,2,3-三氮唑化合物的 方法. 该方法采用叔丁基醇锂为碱, 都涉及 C-5 铜三唑 中间体的反应历程(Scheme 26).

2019 年, $\mathrm{Li}$ 课题组 ${ }^{[26]}$ 报道了一种氧化亚铜催化炔酸 与烷基叠氮化物进行脱羧/环加成反应构建 $N^{1}$-取代-

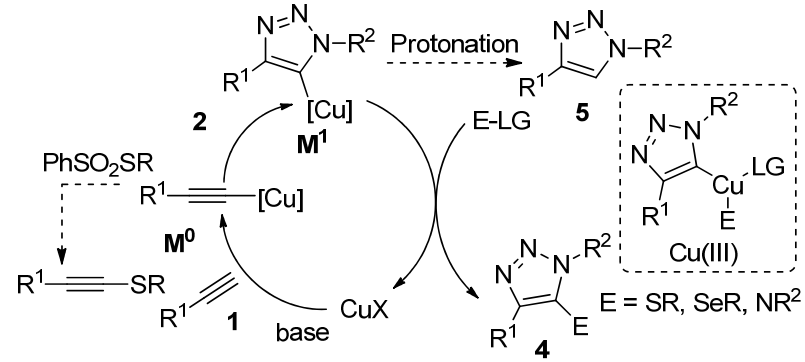

图式 25 构建 $N^{1}$-烷基-5-硫/硒代/氨基取代 1,2,3-三氮唑反应 机理

Scheme 25 Reaction mechanism for the construction of $\mathrm{N}$ alkyl-5-thio/selenyl/amino-1,2,3-triazoles

(a)

$$
\begin{aligned}
& \mathrm{R}^{1}-\mathrm{N}_{3}+\mathrm{R}^{2} \equiv+\mathrm{Br}=\mathrm{R}^{3} \\
& \text { (b) }
\end{aligned}
$$

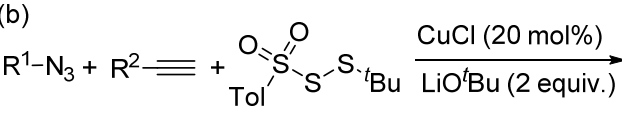

$$
\begin{aligned}
& {\left[\mathrm{R}_{\mathrm{A}}^{2} \stackrel{\mathrm{Cu}}{\mathrm{N}=\mathrm{N})}_{\mathrm{N}-\mathrm{R}^{1}}^{\mathrm{N}}\right]}
\end{aligned}
$$

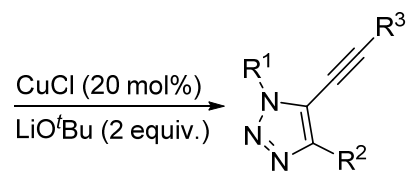

图式 26 合成 $N^{1}$-烷基-5-炔基-1,2,3-三氮唑和 $N^{1}$-烷基-5-二硫1,2,3-三氮唑的方法

Scheme 26 Methods for the synthesis of $N^{1}$-alkyl-5-alkynyl1,2,3-triazoles and $N^{1}$-alkyl-5-persulfur triazoles.

1,2,3-三氮唑的方法. 该反应具有良好的官能团耐受性 和广泛的底物范围, 为 $N^{1}$-取代-1,2,3-三唑提供了一种 有效的合成方法(Scheme 27).

$$
\mathrm{R}^{1}=\mathrm{COOH}+\mathrm{R}^{2}-\mathrm{N}_{3} \stackrel{\mathrm{Cu}_{2} \mathrm{O}, 80^{\circ} \mathrm{C}}{\longrightarrow} \mathrm{R}^{1} \stackrel{\mathrm{N}=\mathrm{N}}{\stackrel{N}{N}-\mathrm{R}^{2}}
$$

图式 27 铜催化炔酸和烷基叠氮反应构建 $N^{1}$-取代-1,2,3-三氮 唑

Scheme 27 Copper catalyzed the reaction of alkyne and alkyl azide to construct $N^{1}$-substituted-1,2,3-triazoles

这种铜催化脱羧环加成反应机理如 Scheme 28 所 示. 以苯丙炔酸与三甲基硅叠氮为例，首先，铜盐与炔 酸进行脱羧反应形成炔基铜中间体 $\mathbf{A}$. 然后，中间体 $\mathbf{A}$ 与叠氮反应经历 $\mathrm{CuAAC}$ 途径形成 C-5 铜三氮唑中间体 C. 最后，中间体 $\mathbf{C}$ 被质子淬灭得到想要的 $N^{1}$-取代$1,2,3$-三氮唑.

\section{$2 \mathrm{NH}-1,2,3-$ 三氮唑为前体构建 $N$-取代-1,2,3 三氮唑}

NH-1,2,3-三氮唑的官能化反应是最直接构建 $N$-取 


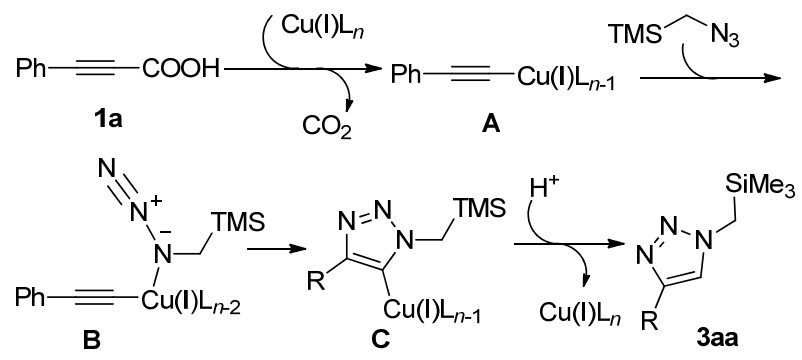

图式 28 构建 $N^{1}$-取代-1,2,3-三氮唑反应机理

Scheme 28 Reaction mechanism for the synthesis of $N^{1}$-substituted-1,2,3-triazoles

代-1,2,3-三氮唑的方法. 采用 NH-1,2,3-三唑后功能化的 方法，可以很好地构建 $N^{1}$-和 $N^{2}$-取代-1,2,3-三唑. 因此, 多个课题组采用金属或非金属催化的方式实现了 NH-1,2,3-三氮唑的直接官能化反应，构建了多种类型 取代的 $N^{1}$-或 $N^{2}$-取代-1,2,3-三氮唑化合物. 原则上, $N^{1}$ 的电子云密度较大, 烷基化和芳基化等占优势. 研究者 利用构型控制及位置控制等策略，可以高效选择性合成 $N^{2}$-取代-1,2,3-三氮唑化合物.

2008 年, 史晓东课题组 ${ }^{[27 a-27 b]}$ 报道了 4,5-二取代$\mathrm{N}(2) \mathrm{H}-1,2,3-$ 三氮唑在碱或铜催化下直接与卤代烷烃、卤 代芳烃和芳基硼酸进行 $N^{2}$-位选择性烷基化和芳基化反 应，合成了一系列 $N^{2}$-取代-1,2,3-三氮唑化合物(Scheme 29 , a， b). 该类反应可通过底物中取代基的位阻效应来 阻止三氮唑的 $N^{1}$-位取代反应的发生. 随后, 王晓俊小 组 ${ }^{[27 \mathrm{c}]}$ 也采用 4,5-二溴- $\mathrm{N}(2) \mathrm{H}-1,2,3$-三氮唑与氟或氯代芳 烃的直接选择性 $\mathrm{N}(2)$-位芳基化反应合成了多种 $N^{2}$-芳 基-1,2,3-三氮唑. 反应进一步通过 $\mathrm{Pd} / \mathrm{C}$ 催化氢化还原消 除 4,5 位的溴原子(Scheme 29, c). 2018 年, 陈云峰课题 组 ${ }^{[27 \mathrm{~d}]}$ 报道了 $\mathrm{I}_{2} \mathrm{O}_{5}$ 介导下 $\mathrm{N}(2) \mathrm{H}-1,2,3$-三氮唑与二甲基亚 砜进行的硫甲基化反应, 得到了 $N^{2}$-甲硫甲基-1,2,3-三 氮唑为主的产物. 该反应会产生少量 $N^{1}$-甲硫甲基$1,2,3-$ 三氮唑.

2015 年, Singh 课题组 ${ }^{[28]}$ 报道了四丁基碘化铵 (TBAI) 催化下 NH-1,2,3-三氮唑和醚或硫醚反应合成 $N^{1}-$ 和 $N^{2}$-氧烷基-1,2,3-三氮唑的方法. 该方法在 $70{ }^{\circ} \mathrm{C}$ 下进 行, 采用过氧化叔丁醇( TBHP)为氧化剂, 具有操作简 单、条件温和及底物适用范围广的优点. 但反应缺少位 置选择性，一般得到 $N^{1}$-和 $N^{2}$-氧烷基-1,2,3-三氮唑混合 物(Scheme 30).

2017 年, 陈云峰课题组 ${ }^{[29]}$ 报道了一种铜催化 NH$1,2,3$-三氮唑和 $N, N$-二烷基酰胺的交叉脱氢反应构建 $N^{2}$-酰胺烷基-1,2,3-三氮唑的方法(Scheme 31). 该反应 以醋酸铜为催化剂, 以过硫酸钾为氧化剂, 以碳酸钠为 碱, 在 $110{ }^{\circ} \mathrm{C}$ 下高效完成多类 $N^{2}$-酰胺烷基-1,2,3-三氮 唑化合物的构建. 该反应具有底物适用性广和反应选择
$N^{2}$-alkylation reaction:

(a)

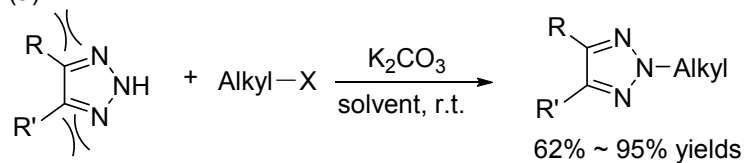

$N^{2}$-arylation reaction:

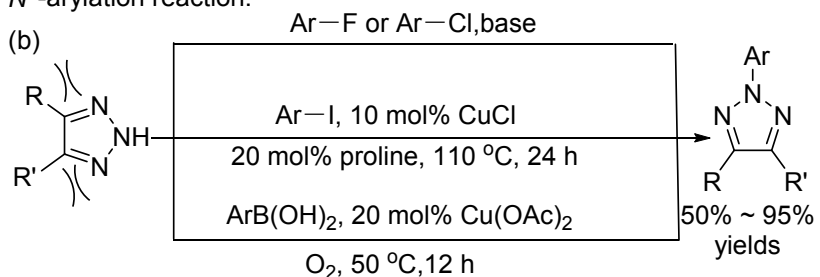

$N^{2}$-arylation reaction:

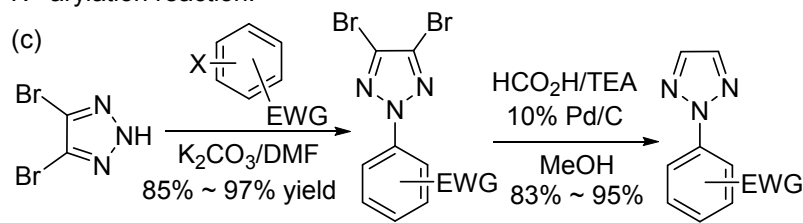

$N^{1}$ - and $N^{2}$-alkylation reaction:

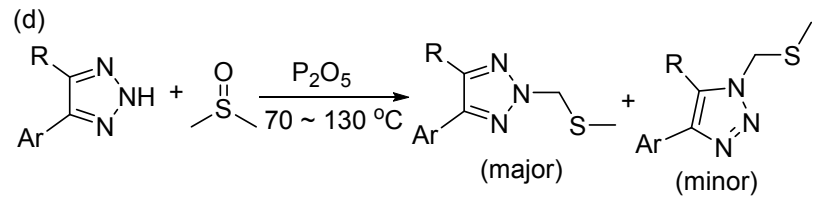

图式 $29 \mathrm{~N}(2) \mathrm{H}-1,2,3$-三氮唑烷基/芳基化反应构建 $N^{2}$-芳基1,2,3-三氮唑

Scheme 29 Alkylation/arylation of $\mathrm{N}(2) \mathrm{H}-1,2,3$-triazoles to construct $N^{2}$-alkyl/aryl-1,2,3-triazoles

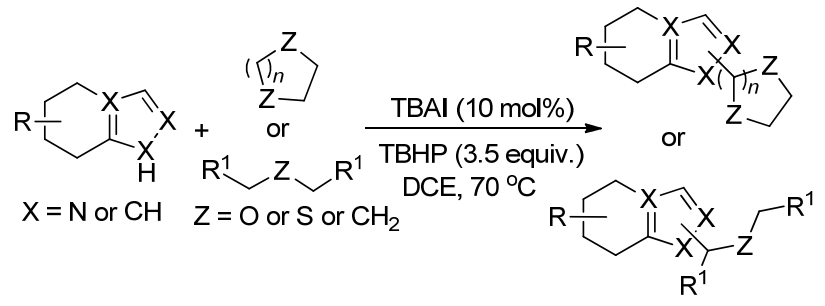

图式 30 TBAI 催化 NH-1,2,3-三氮唑和醚反应构建 $N^{1}$-和 $N^{2}$ 氧烷基-1,2,3,-三氮唑

Scheme 30 TBAI catalyzed reaction of NH-1,2,3-triazole and ether to construct $N^{1}$ - and $N^{2}$-substituted-1,2,3-triazoles

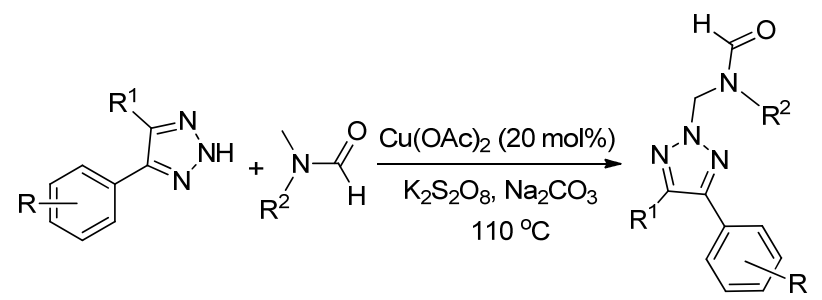

图式 31 NH-1,2,3-三氮唑和烷基酰胺反应构建 $N^{2}$-酰胺烷基1,2,3-三氮唑

Scheme 31 Reaction of NH-1,2,3-triazole with alkyl amide to construct $N^{2}$-amidoalkylated-1,2,3-triazoles 
性好等优点, 为 $N^{2}$-取代-1,2,3-三氮唑提供了一种有效 的合成策略.

铜催化 NH-1,2,3-三氮唑和酰胺反应可能的机理如 Scheme 32 所示: 首先, $N, N$-二甲基甲酰胺在 $\mathrm{Cu}(\mathrm{II})$ 氧化 下产生自由基阳离子 $\mathbf{A}$, 其进一步被 $\mathrm{Cu}(\mathrm{II}) / \mathrm{K}_{2} \mathrm{~S}_{2} \mathrm{O}_{8}$ 氧化 夺氢生成亚胺离子 $\mathbf{B}$. 然后, 三氮唑 $1 \mathbf{a}$ 的 N-2 位选择性 对亚胺离子 $\mathbf{B}$ 进行亲核加成反应得到中间体 C. 最后, 中间体 $\mathbf{C}$ 失去氢离子形成产物 $N^{2}$-酰胺烷基-1,2,3-三氮 唑 3a.

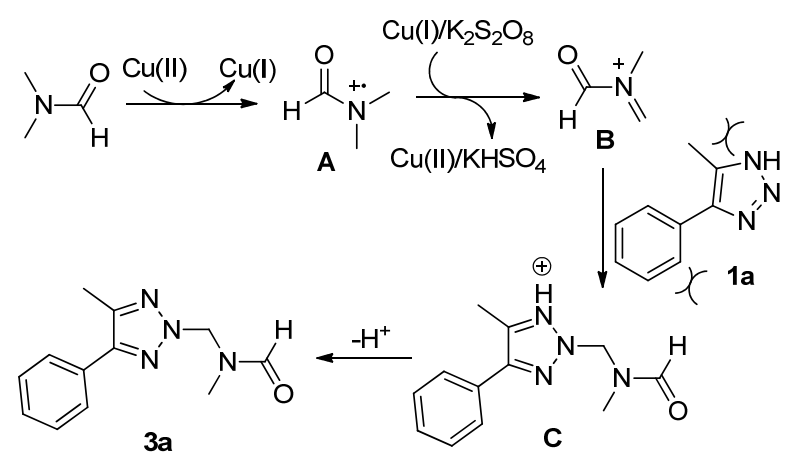

图式 32 构建 $N^{2}$-酰胺烷基-1,2,3-三氮唑反应机理 Scheme 32 Reaction mechanism for the synthesis of $N^{2}$-amidoalkylated-1,2,3-triazoles

2017 年, 雷爱文课题组 ${ }^{[30]}$ 报道了光催化 NH-1,2,3三氮唑和醚反应构建 $N^{1}$-烷氧基-1,2,3-三氮唑化合物的 方法(Scheme 33). 该方法具有反应条件温和、操作简 单、底物范围广及无金属催化剂等优点, 为各种 $N^{1}$-烷 氧基-1,2,3-三氮唑提供了一种高效的合成策略.

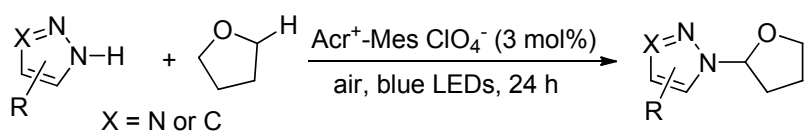

图式 33 光催化 $\mathrm{NH}$-三氮唑和醚反应构建 $N$-烷氧基-1,2,3-三 氮唑

Scheme 33 Visible-light-catalyzed reaction of NH-1,2,3triazole and ether to construct $N$-oxyalkylated-1,2,3- triazoles

该反应机理如 Scheme 34 所示: 首先, 光催化剂 $\mathrm{Acr}^{+}-\mathrm{MesClO}_{4}{ }^{-}$被可见光激发照射 $(3 \mathrm{~W}$ 蓝色 $\mathrm{LED}$ 光)生 成激发态物质 $\left[\mathrm{Acr}^{+}-\mathrm{MesClO}_{4}{ }^{-}\right]^{*}$, 然后与 $\mathrm{NH}$ 三氮唑进 行单电子转移(SET)过程以生成氮中心自由基 4 和 $\left[\mathrm{Acr}^{+}-\mathrm{MesClO}_{4}{ }^{-}\right]$自由基阴离子. 随后, $\mathrm{O}_{2}$ 氧化 $\left[\mathrm{Acr}^{+}-\right.$ $\mathrm{MesClO}_{4}{ }^{-}$]自由基阴离子生成超氧化物 $\mathrm{O}_{2}{ }^{-}$和基态光催 化剂. 生成的超氧化物 $\mathrm{O}_{2}{ }^{-}$夺取醚 $\alpha$-碳上的氢形成 $\alpha$-碳 自由基 5. 最后, 在 $\mathbf{5}$ 经过路径 $\mathrm{a}$ 或 $\mathrm{b}$ 得到相应的 $N^{1}$-烷 氧基- 1,2,3-三氮唑.

同年，雷爱文课题组 ${ }^{[31]}$ 又报道了电催化 $\mathrm{NH}$ 三氮唑 和烷烃反应构建 $N^{1}$-烷基-1,2,3-三氮唑的方法(Scheme

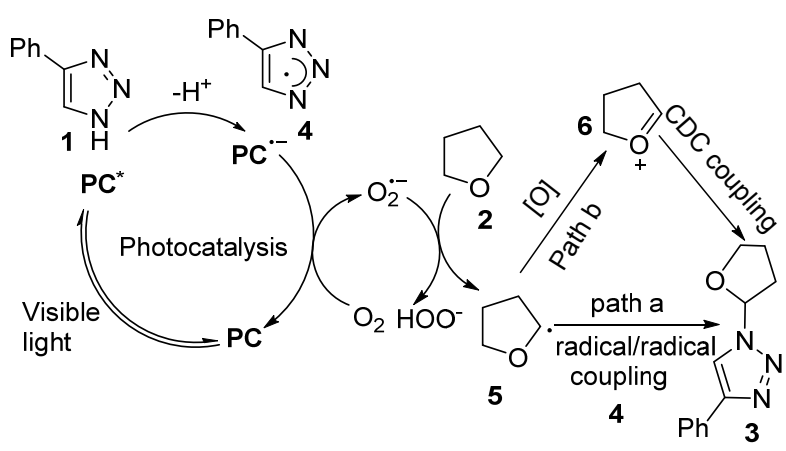

图式 34 光催化 NH-三氮唑和醚反应机理

Scheme 34 Mechanism for visible-light-catalyzed reaction of NH-1,2,3-triazole and ether
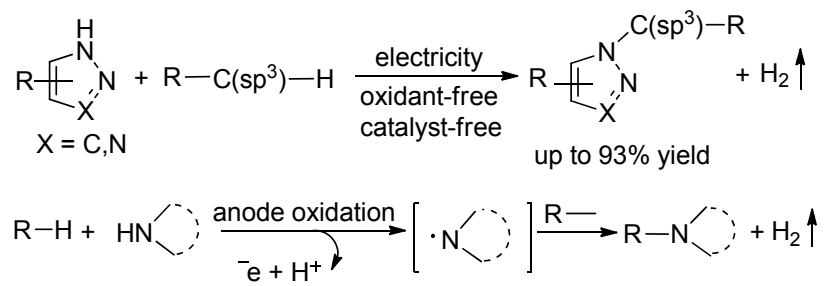

图式 35 电催化构建 $N^{1}$-烷基-1,2,3-三氮唑化合物的反应 Scheme 35 Electrocatalytic reaction for the construction of $N^{1}$ alkyl-1,2,3-triazoles

35). 该反应首先通过单电子转移和随后的氢转移过程, 由阳极氧化形成氮自由基. 然后，氮自由基与四氢呋喃 反应进行交叉偶联反应得到 $N^{1}$-烷基取代-1,2,3-三氮唑 化合物. 同时，质子氢的阴极还原导致氢气的形成.

2018 年, Breit 课题组 ${ }^{[32]}$ 报道了一种铑催化炔烃和 联烯与 NH-1,2,3-三氮唑反应选择性构建 $N^{1}$-和 $N^{2}$-烯丙 基取代-1,2,3-三氮唑的方法(Scheme 36). 该方法通过配 体和添加剂的调控，可以有效控制反应的化学选择性, 高效合成 $N^{1}$-和 $N^{2}$-烯丙基-1,2,3-三氮唑化合物.
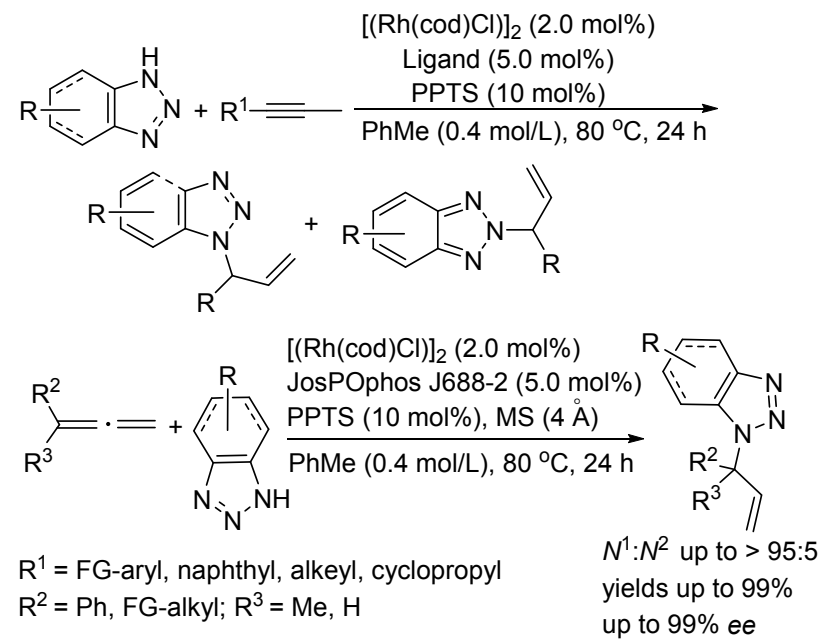

图式 $36 \mathrm{NH}-1,2,3$-三氮唑与炔烃/联烯反应构建 $N^{1}$-和 $N^{2}$-位烯 丙基取代-1,2,3-三氮唑

Scheme 36 Reaction of NH-1,2,3-triazoles with alkyne/alkene to $N^{1}$ - and $N^{2}$-allyl-1,2,3-triazoles 
2018 年, 赵志刚课题组 ${ }^{[33]}$ 报道了一种 $\mathrm{Ph}_{3} \mathrm{PAuCl} /$ $\operatorname{AgNTf}(5 \mathrm{~mol} \%$ ) 催化 NH-1,2,3-三氮唑与烯基醚选择性 反应构建 $N^{2}$-烷基-1,2,3-三氮唑的方法. 该反应以 $1,2-二$ 氯乙烷(DCE)为溶剂, 在 $80{ }^{\circ} \mathrm{C}$ 下反应可以得到多种链 状和环状氧烷基-1,2,3-三氮唑化合物，具有操作简单、 底物适用性广和选择性高的优点(Scheme 37).

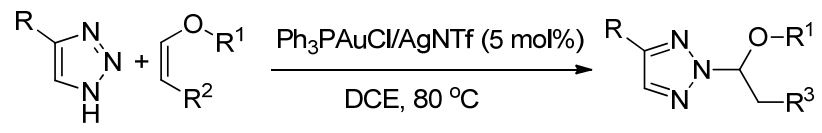

图式 $37 \mathrm{NH}-1,2,3$-三氮唑和烯基醚反应构建 $N^{2}$-氧烷基-1,2,3三氮唑

Scheme 37 Reaction of NH-1,2,3-triazole and vinyl ether to construct $N^{2}$-oxyalkyl-1,2,3-triazoles

两种可能的反应机理如 Scheme 38 所示: 途径 A 涉 及 $\mathrm{Au}(\mathrm{I})$ 配位活化烯基醚 $\mathbf{2 a}$, 然后, NH-1,2,3-三氮唑与 烯基醚形成氢键. 进一步, 1,2,3-三氮唑 $N^{2}$ 位对其进行亲 核加成反应. 最后, 消除金属得到 $N^{2}$-氧烷基-1,2,3-三唑 3a. 氮原子通过氢键相互作用形成烷基中间体. 随后其 进行金属脱除得到 $N^{2}$-氧烷基-1,2,3-三唑 3a. 途径 $\mathrm{B}$ 是 经过 $\mathrm{Au}(\mathrm{I})$ 配位活化 $\mathrm{NH}-1,2,3$-三氮唑, 然后与烯基醚反 应得到 $N^{2}$-氧烷基-1,2,3-三氮唑化合物.

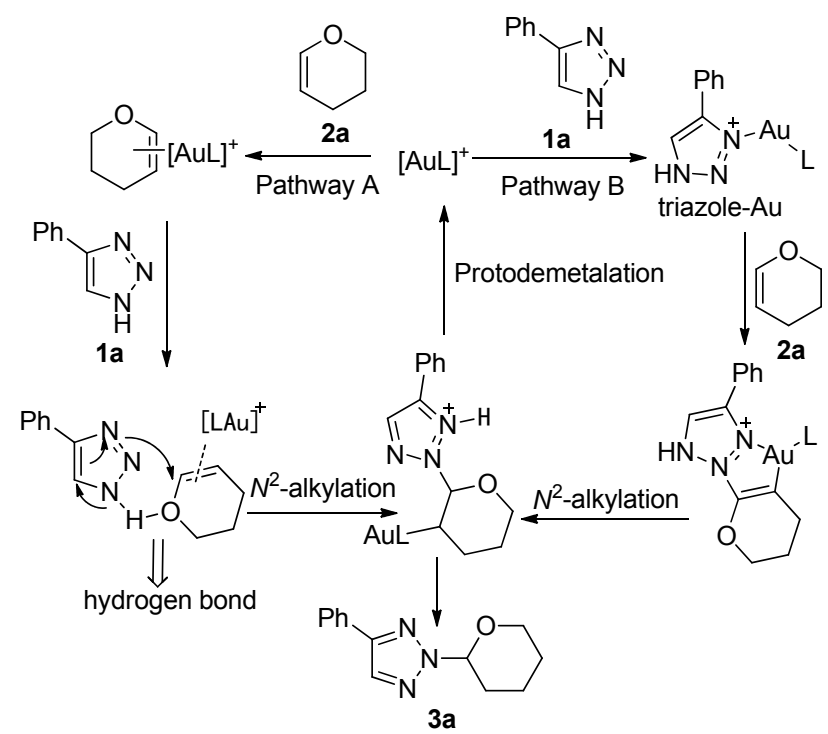

图式 $38 \mathrm{NH}-1,2,3$-三氮唑和烯基醚反应机理

Scheme 38 Reaction mechanism for the reaction of $\mathrm{N}(\mathrm{H})$ 1,2,3-triazole and vinyl ether

\section{3 腙为氮源构建 $N$-取代-1,2,3-三氮唑}

大多数 $N$-取代-1,2,3-三氮唑的合成都是采用叠氮化 物或 NH-1,2,3-三氮唑为氮源. 近年来, 化学家发展了多 类腙为氮源代替叠氮化物合成 $N^{1}$-取代-1,2,3-三氮唑的 方法 ${ }^{[34]} .2010$ 年, Hanselmann 课题组 ${ }^{[35]}$ 报道了一种二异
丙基乙基胺(DIPEA)介导下以 $\alpha, \alpha$-二氯对甲苯磺酰基取 代的腙为氮源与一级胺进行环合反应构建 $N^{1}$-取代1,2,3-三氮唑的方法. 采用该方法在乙醇溶剂中可以合 成具有抗菌活性的 $N^{1}$-取代-1,2,3-三氮唑 3a (Scheme 39). 随后, Westermann 等 ${ }^{[36]}$ 对其反应条件做了改进，采 用了乙腈和乙醇混合溶剂使得反应底物范围更加广泛 (Scheme 40).

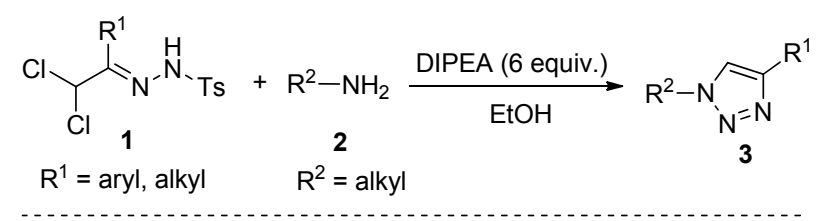<smiles>CCOC(=O)CCc1cn([C@@H](CF)[C@H](OC)c2ccc(-c3cnc(N)nc3)cc2)nn1</smiles>

图式 39 合成抗菌活性的 $N^{1}$-取代-1,2,3-三氮唑化合物 Scheme 39 Synthesis of an antibacterial compound containing $N^{1}$-substituted-1,2,3-triazole framework

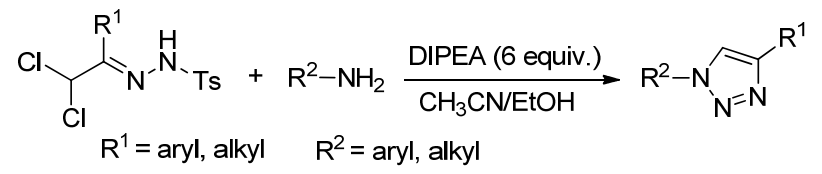

图式 40 腙和胺反应合成 $N^{1}$-取代-1,2,3-三氮唑 Scheme 40 Reaction of $\alpha, \alpha$-dichlorotosylhydrazone and amine to synthesize $N^{1}$-substituted-1,2,3-triazole

该反应机理如 Scheme 41 所示: 首先, $\alpha, \alpha$-二氯对甲 苯磺酰基腙 1 在碱作用下通过消除反应转化为中间体 $\mathbf{A}$, 然后其与胺进一步进行反应，并失去对甲苯磺酸根 离子得到中间体 B. 接着, 中间体 $\mathbf{B}$ 进行去质子化和环 化反应生成三氮唑产物 3 . 另一种可能的路径是的两个 化合物 $\mathbf{B}^{\prime}$ 和 $\mathbf{C}^{\prime}$ 中对甲苯磺酰基保留，在碱作用下经过 中间体 $\mathbf{C}^{\prime \prime}$ 得到相应的产物。

上述方法的一个缺点就是原料 $\alpha, \alpha$-二氯对甲苯磺酰 基取代的腙难以制备和操作 ${ }^{[37]} .2013$ 年, 张玉红课题 组 ${ }^{[38]}$ 解决了这一难题，他们以 $N$-对甲磺酰基腙为氮源, 在 $\mathrm{Cu}(\mathrm{OAc})_{2}$ 介导下与一级胺进行环合反应构建了 $N^{1}$ 取代-1,2,3-三氮唑. 该反应以三甲基乙酸为添加剂，甲 苯为溶剂, $100{ }^{\circ} \mathrm{C}$ 下完成多种 $N^{1}$-芳基取代-1,2,3-三氮唑 的构建(Scheme 42).

反应机理如 Scheme 43 所示: 首先, $N$-对甲磺酰基 


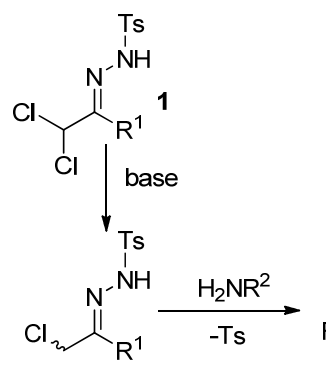

A

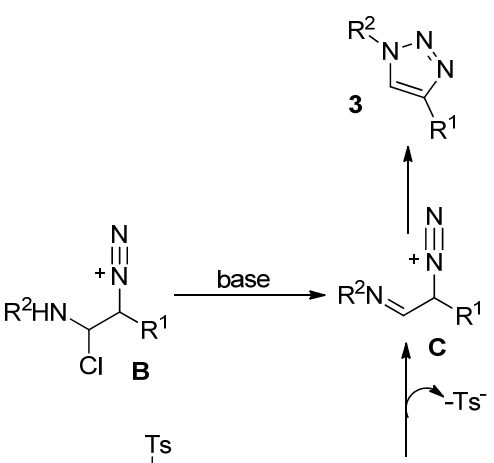<smiles>[R]/C(=N\N[Te]C)C([R2])Cl</smiles><smiles>[R10]C/C([R1])=N/N[13CH3]</smiles><smiles>[R]C(C=[W])[N+]=[W]</smiles>

图式 41 腙和胺反应合成 $N^{1}$-取代-1,2,3-三氮唑机理 Scheme 41 Mechanism for reaction of $\alpha, \alpha$-dichlorotosylhydrazone and amine to access $N^{1}$-substituted-1,2,3-triazole

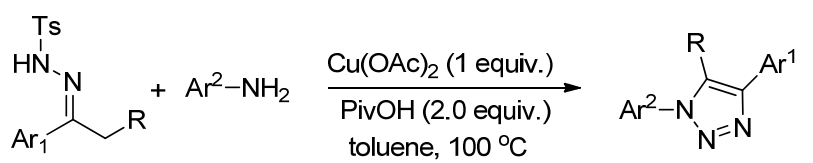

图式 42 铜催化 $N$-对甲苯磺酰腙和胺反应合成 $N^{1}$-取代-1,2,3三氮唑

Scheme 42 Copper catalyzed reaction of $N$-tosylhydrazone and aniline to build $N^{1}$-substituted-1,2,3-triazoles
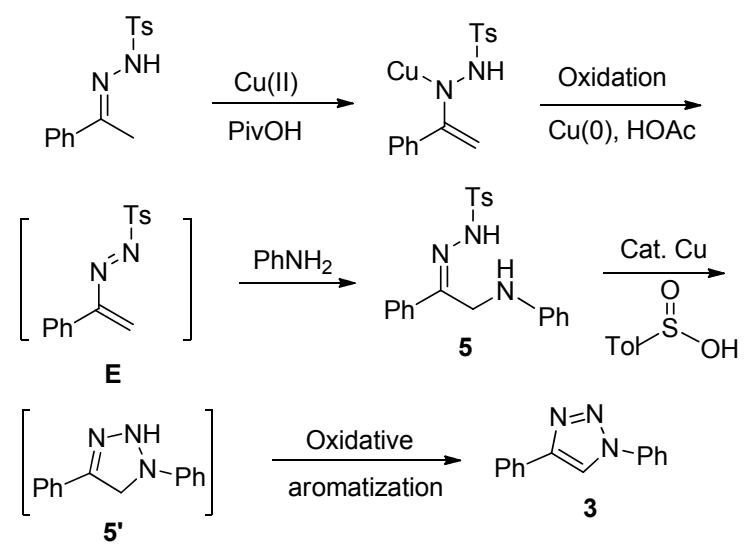

图式 43 铜催化 $N$-对甲苯磺酰腙和胺反应机理

Scheme 43 Mechanism for copper catalyzed reaction of $N$-tosylhydrazone and aniline

腙在 $\mathrm{Cu}(\mathrm{OAc})_{2}$ 和 $\mathrm{PivOH}$ 的帮助下异构成中间体 $\mathbf{D}$, 其 接着被氧化为烯基偶氮中间体 $\mathbf{E}$. 然后，中间体 $\mathbf{E}$ 和芳 胺进行 aza-Michael 加成反应形成化合物 $\mathbf{5}$, 其在铜催化 下失去对甲苯磺酸, 得到中间体 $\mathbf{5}^{\prime}$, 最后通过氧化芳构 化反应得到最终的产物 $\mathbf{3}$.

随后, 纪顺俊课题组 ${ }^{[39]}$ 报道了一种可以 $\mathrm{I}_{2} / \mathrm{TBPB}$ (过 氧化苯甲酸特丁酯) 体系介导下 $N$-对甲苯磺酰腙和芳胺
来构建 $N^{1}$-芳基-1,2,3-三氮唑的方法(Scheme 44). 该方 法用催化量的 $\mathrm{I}_{2}$ 为催化剂, 以 $\mathrm{TBPB}$ 为氧化剂, 不使用 任何金属催化剂. 多种 $N^{1}$-芳基取代-1,2,3-三氮唑都可 以获得中等至较好的收率且具有广泛的官能团兼容性.

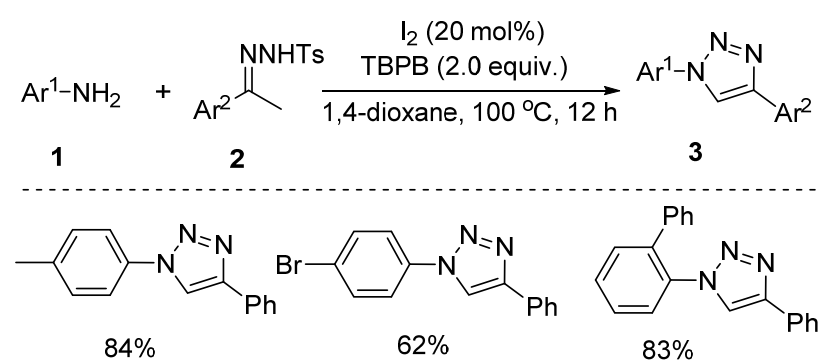<smiles>CC(=O)OCC=Cc1ccccc1-n1cc(-c2ccccc2)nn1</smiles>

图式 $44 \mathrm{I}_{2} / \mathrm{TBPB}$ 介导合成 $N^{1}$-取代-1,2,3-三氮唑 Scheme $44 \mathrm{I}_{2} / \mathrm{TBPB}$ mediated construction of $N^{1}$-substituted-1,2,3-triazoles

$\mathrm{I}_{2} / \mathrm{TBPB}$ 体系介导反应机理如 Scheme 45 所示: 在 碘作用下 $N$-对甲苯磺酰腙进行 $\alpha$-碘化反应形成中间体 4'，其脱除 HI 形成偶氮烯中间体 E. E 和芳胺进行 aza-Michael 反应得到化合物 $\mathbf{5}$, 化合物 $\mathbf{5}$ 被 $\mathrm{I}_{2} / \mathrm{TBPB}$ 氧 化生成自由基阳离子 $\mathbf{H}^{\prime}$. 然后, 其进行分子内 $\mathrm{N}-\mathrm{N}$ 键 偶联反应得到中间体 $\mathbf{5}^{\prime}$. 最后，5'通过氧化脱除磺酰基 得到 $N^{1}$-芳基取代-1,2,3-三氮唑 3 .

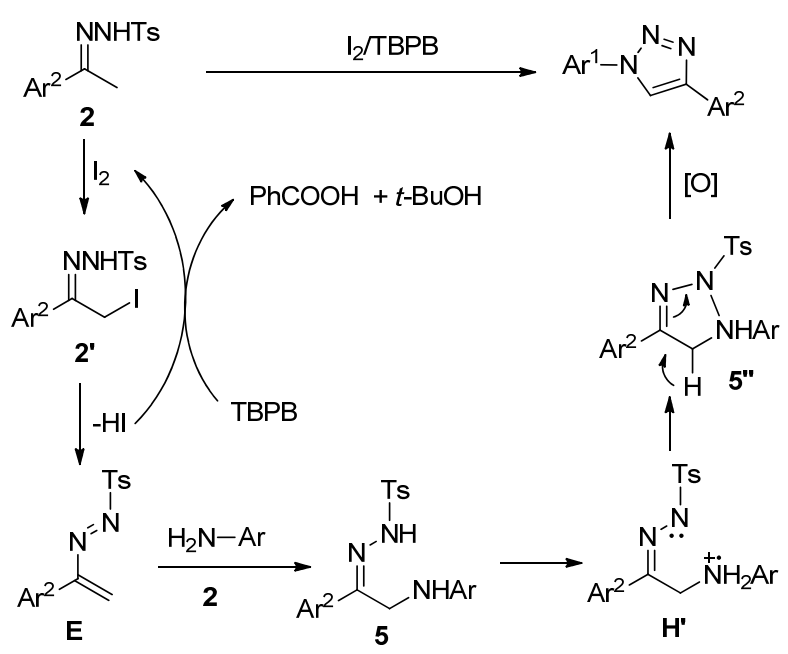

图式 $45 \mathrm{I}_{2} / \mathrm{TBPB}$ 介导合成 $N^{1}$-取代-1,2,3-三氮唑反应机理 Scheme 45 Mechanism for $I_{2} /$ TBPB mediated construction of $N^{1}$-substituted-1,2,3-triazoles

2012 年, Punniyamurthy 课题组 ${ }^{[40]}$ 发展了一种氧气 条件下铜催化二芳基腙合成 2,4,5-三芳基-1,2,3-三氮唑 
的方法(Scheme 46). 该方法采用催化量的 $\mathrm{Cu}(\mathrm{OAc})_{2}$ 为 催化剂, 通过连续的 $\mathrm{C}-\mathrm{H}$ 官能化, $\mathrm{C}-\mathrm{C}, \mathrm{N}-\mathrm{N}$ 和 $\mathrm{C}-\mathrm{N}$ 键形成反应得到一系列 $N^{2}$-芳基-1,2,3-三氮唑.

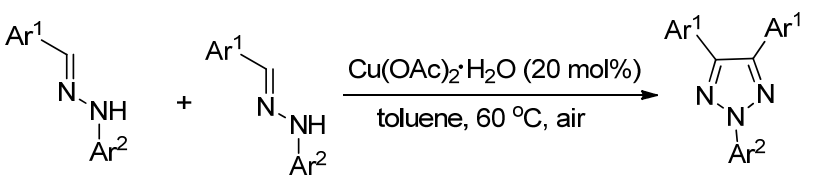

图式 46 铜催化需氧氧化合成 $N^{2}$-取代-1,2,3-三氮唑 Scheme $46 \mathrm{Cu}(\mathrm{II})$-catalyzed aerobic oxidative synthesis of $N^{2}$-substituted-1,2,3-triazoles

\section{4 磺酰肼为氮源构建 $N$-取代-1,2,3-三氮唑}

磺酰肼作为重要的化工原料常被用作构建各种含 氮化合物. 2014 年, 张玉红课题组 ${ }^{[41]}$ 报道了非金属介导 下一级胺、芳香酮和磺酰肼三组分反应构建 $N^{1}$-取代1,2,3-三氮唑的方法 (Scheme 47). 该方法通过连续的形 成 $\mathrm{C}-\mathrm{N}$ 和 $\mathrm{N}-\mathrm{N}$ 键进而构建多种类型的 1,4-二取代1,2,3-三氮唑. 该反应条件温和, 不需要金属试剂和叠氮 化物为氮源.

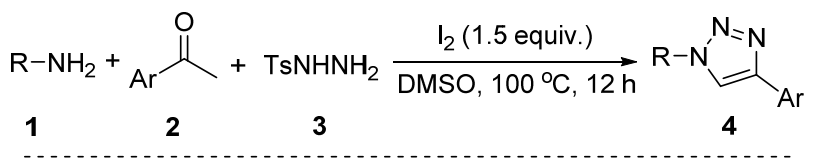<smiles>FC(F)(F)c1cccc(-c2cn(-c3ccccc3)nn2)c1</smiles>

$84 \%$

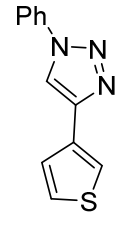

$79 \%$

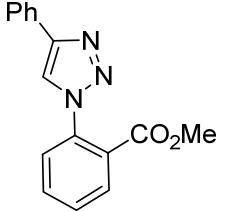

$90 \%$

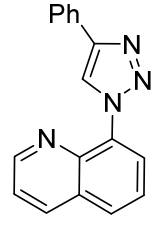

$64 \%$
图式 $47 \mathrm{I}_{2}$ 介导胺、芳香酮和磺酰肼三组分反应合成 $N^{1}$-取 代-1,2,3-三氮唑

Scheme $47 \quad \mathrm{I}_{2} / \mathrm{TBPB}$ mediated three-component reaction of arylketone, amine and tosylhydrazine to construct $N^{1}$-substituted1,2,3-triazoles

Scheme 48 展示了两种可能的反应路径. 路径 A: 在碘和二甲基亚砜作用下苯乙酮 $2 \mathbf{a}$ 被氧化生成酮醛. 然后, 其与胺进行缩合反应形成中间体 $\mathbf{J}$. 中间体 $\mathbf{J}$ 与 对甲苯磺酰肼反应得到中间体 $\mathbf{K}$, 最后, 中间体 $\mathbf{K}$ 经过 脱磺酰基及环合反应得到想要的产物 4a. 路径 B: 苯乙 酮 2a 与对甲苯磺酰肼进行缩合反应得到 $N$-对甲苯磺酰 腙 5a, 5a 进行 $\alpha$-碘化反应形成中间体 5a', 其脱除 HI 形 成偶氮烯中间体 E. E 和芳胺进行 aza-Michael 反应生成 化合物 6a. 最后, $6 \mathbf{a}$ 通过氧化环化脱除磺酰基得到 1,2,3-三氮唑 4a.

2015 年, 万结平课题组 ${ }^{[42 \mathrm{a}]}$ 发展了一种非金属碘催

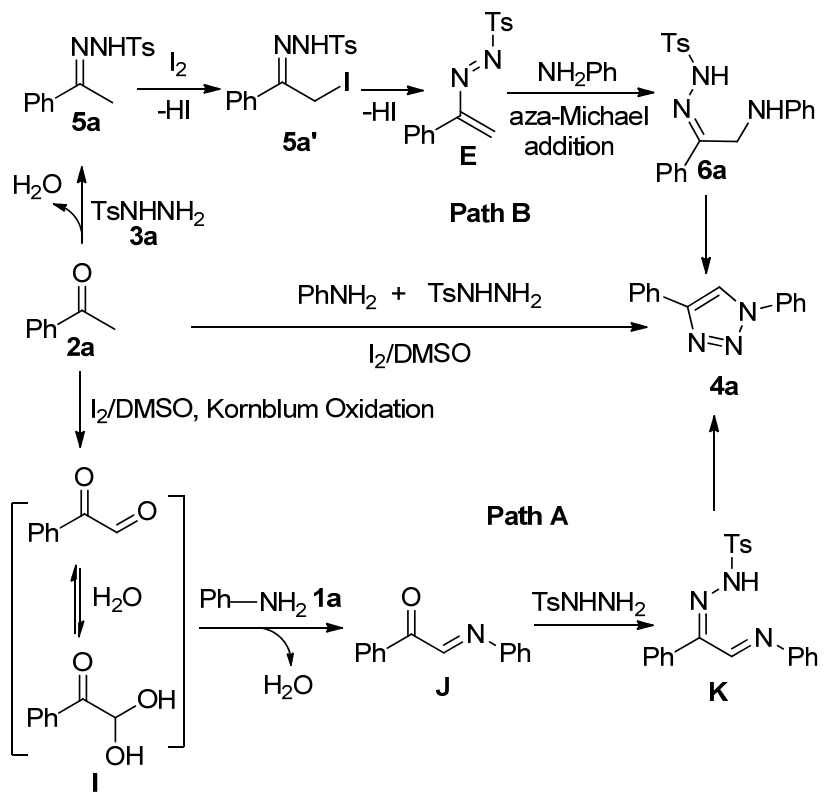

图式 $48 \mathrm{I}_{2}$ 介导胺、芳香酮和磺酰肼三组分反应机理 Scheme 48 Mechanism for $\mathrm{I}_{2} / \mathrm{TBPB}$ mediated three-component reaction of arylketone, amine and tosylhydrazine

化下烯胺酮、一级胺和对甲苯磺酰肼三组分反应构建 $N^{1}$-取代-1,2,3-三氮唑的方法(Scheme 49). 该策略通过 连续的 $\mathrm{C}-\mathrm{N}$ 键和 $\mathrm{N}-\mathrm{N}$ 键形成以及酰基迁移来完成, 并以中等至较好的收率合成了多种 $N^{1}$-取代-1,2,3-三氮 唑. 2016 年, Dehaen 课题组 ${ }^{[42 b]}$ 采用芳香甲基酮和 $N, N$ 二甲基甲酰胺二甲基缩醛生成的烯胺酮中间体，“一锅 法” 与有机叠氮在加热条件下反应也可以高效地生成 $N^{1}$-取代-1,2,3-三氮唑.

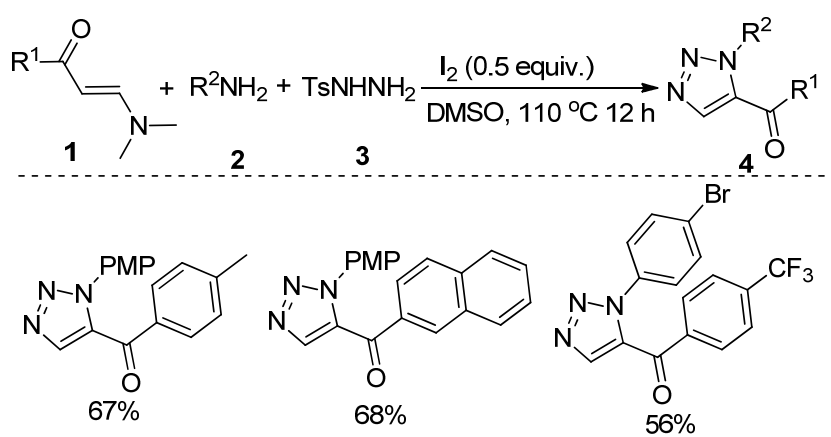

图式 49 碘催化合成烯胺酮、一级胺和对甲苯磺酰肼三组分 反应构建 $N^{1}$-取代-1,2,3-三氮唑

Scheme $49 \quad I_{2}$ catalyzed three-component reaction of enaminones, primary amines and tosylhydrazine to construct $N^{1}$-substituted-1,2,3-triazoles

\section{5 重氮化物为氮源构建 $N$-取代-1,2,3-三氮唑}

重氮化物具有较高的反应活性，其在有机合成中有 着广泛的应用价值. 2015 年, 赵玉龙课题组 ${ }^{[43]}$ 报道了一 种铜催化二级胺与重氮化合物的 $[3+2]$ 环加成反应构建 
$N^{1}$-取代-1,2,3-三氮唑的方法(Scheme 50), 该反应利用 氧气作为绿色的氧化剂, 具有原料易得、条件温和、官 能团兼容性好等优点, 为多种 $N^{1}$-取代-1,2,3-三氮唑提 供了一个实用的合成方法.

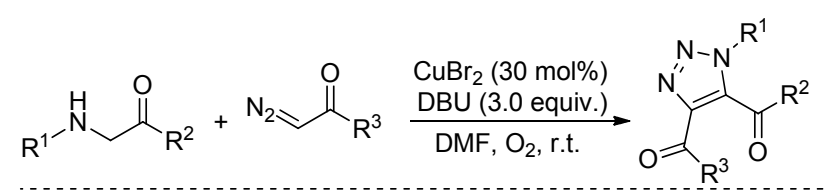<smiles>CCOC(=O)c1nnn(-c2ccc3ccccc3c2)c1C(=O)OCCCCCC(=O)c1ccccc1</smiles><smiles></smiles>

图式 50 铜催化 $\alpha$-氨基酮和重氮化物 $[3+2]$ 环加成反应合成 $N^{1}$-取代-1,2,3-三氮唑

Scheme 42 Cu-catalyzed oxidative [3+2] cycloaddition reaction of $\alpha$-aminoketones and diazo compounds for the synthesis of $N^{1}$-substituted-1,2,3-triazoles

可能的反应机理如 Scheme 51 所示. 首先, 胺 1 通 过单电子转移进程被 $\mathrm{CuBr}_{2}$ 氧化形成胺自由基阳离子 A. 然后, 氢自由基转移形成亚胺阳离子 $\mathbf{B}$, 亚胺阳离子 $\mathbf{B}$ 与 $\alpha$-重氮化合物 2 进行[3+2]环加成反应得到中间体 C. 最后, 中间体 $\mathbf{C}$ 在氧气下被 $\mathrm{CuBr}_{2}$ 氧化生成 $N^{1}$-取 代-1,2,3-三氮唑 3.<smiles>[R]CCC(=O)CN[R]</smiles>

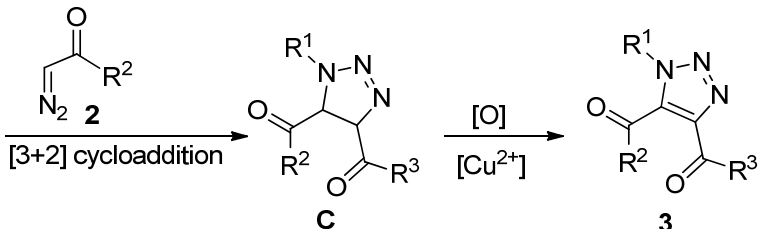

图式 51 铜催化 $\alpha$-氨基酮和重氮化物 [3+2]环加成反应机理 Scheme 51 Mechanism for $\mathrm{Cu}$-catalyzed oxidative [3+2] cycloaddition reaction of $\alpha$-aminoketone and diazo compound

2015 年, 马军安课题组 ${ }^{[44]}$ 报道了一种便捷的银催 化异腈与重氮化物 $[3+2]$ 环加成反应合成 $N^{1}$-取代-1,2,3三氮唑的方法(Scheme 52). 虽然, Kiselyov 课题组 ${ }^{[45]}$ 早
在 2006 年报了一种相关的异腈与重氮化物与 $N$-氟代吡 啶盐的环加成反应，但是该反应仅得到 $1,2,3$-三氮唑与 其它化合物的混合物. 马军安课题组报道的 $\mathrm{Ag}_{2} \mathrm{CO}_{3}$ 催 化异腈与 2,2,2-三氟甲基重氮甲烷反应可以在温和条件 下高效形成多种 4-三氟甲基- $N^{1}$-烷基-1,2,3-三氮唑.

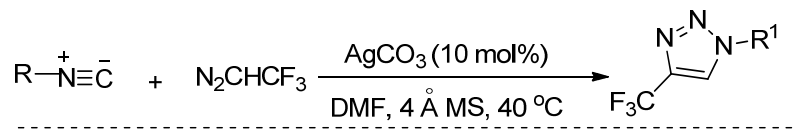<smiles>FC(F)(F)c1ccc(-n2cc(C(F)(F)F)nn2)cc1</smiles><smiles>COc1ccc(-n2cc(C(F)(F)F)nn2)c(OC)c1</smiles>

图式 52 银催化异腈和重氮化物 $[3+2]$ 环加成反应合成 $N^{1}$-取 代-1,2,3-三氮唑

Scheme 52 Silver-catalyzed cycloaddition of isocyanide with diazo compound to construct $N^{1}$-substituted-1,2,3-triazoles

可能的反应机理如 Scheme 53 所示. 首先, 异腈 1 与 $\mathrm{Ag}^{+}$反应生成银异腈化合物 $\mathbf{A}$. 然后, $\mathbf{A}$ 与 2,2,2-三氟 甲基重氮甲烷进行 1,3-偶极环加成反应形成中间体 B. B 异构化得到银卡宾化合物, 接着被去质子化形成中间体 C. 最后, 中间体 $\mathbf{C}$ 进行氢化还原脱除银历程生成 $N^{1}-$ 取代-1,2,3-三氮唑 3 .
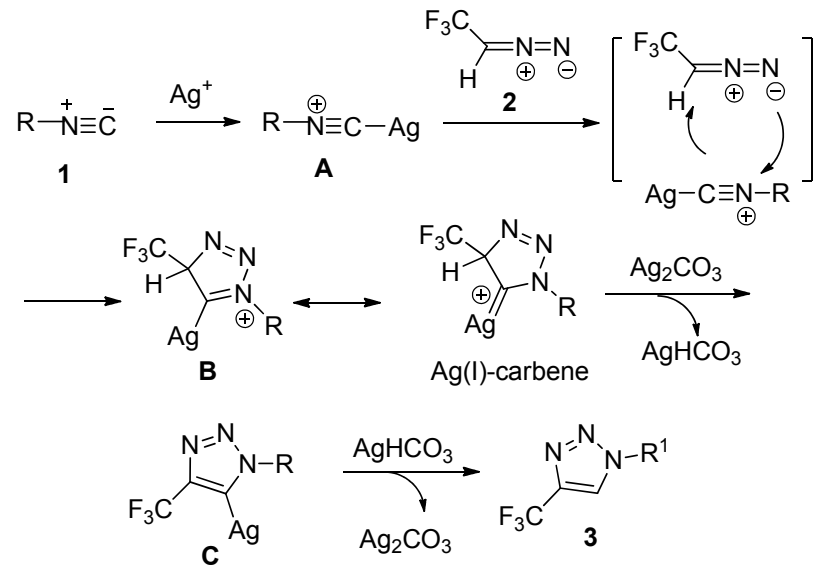

图式 53 银催化异腈和重氮化物 $[3+2]$ 环加成反应机理 Scheme 53 Mechanism for silver-catalyzed cycloaddition of isocyanide with diazo compound

2016 年, Mohanan 课题组 ${ }^{[46]}$ 报道了一种高效、简便 的基于三组分反应合成 1,4,5-三取代三氮唑的方法 (Scheme 54). 该反应使用廉价且容易获得的醛、胺和 Bestmann-Ohira 试剂(BOR，二甲基 $\alpha$-重氮- $\beta$-氧代丙基 磷酸酯)为原料, 为 4-磷酰基- $N^{1}$-取代-1,2,3-三氮唑提供 了一个高效的合成策略. 鉴于这类杂环化物在农药和制 
药行业的重要性, 预计这种合成膦酰基-1,2,3-三氮唑的 新方法将具有潜在的应用价值.

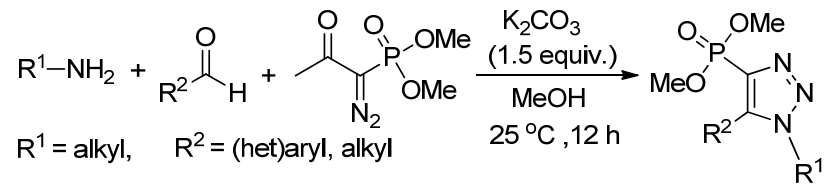

图式 54 醛、胺和二甲基 $\alpha$-重氮- $\beta$-氧代丙基磷酸酯三组分反 应合成 $N^{1}$-取代-1,2,3-三氮唑

Scheme 54 Reaction of amine, aldehyde and dimethyl $\alpha$-diazo$\beta$-oxopropylphosphonate to synthesize $N^{1}$-substituted-1,2,3-triazoles

\section{6 总结和展望}

鉴于 $N$-取代-1,2,3-三氮唑结构单元在医药和材料领 域的大量应用, $N$-取代-1,2,3-三氮唑类化合物的合成近 年来取得一系列重要的进展. 总结了以叠氮化物(叠氮 化钠、叠氮三甲基硅烷、烷基/芳基叠氮)、腙、磺酰肼 和重氮为氮源以及 $\mathrm{NH}-1,2,3$-三氮唑为前体构建具有重 要价值的 $N$-取代-1,2,3-三氮唑的方法. 根据不同的底物 及反应条件, 分别从合成方法和反应机理进行分析、归 纳和总结. 目前, 该领域主要还是采用叠氮化物为氮源 的合成策略，其大都使用金属铜或钯盐为催化剂且反应 条件相对苛刻. 相信随着研究的不断深入, 其它一些非 叠氮试剂和非金属催化剂以及简洁、温和的合成方法如 光催化和电催化策略将会被不断发展, 合成路线也一定 会更加绿色经济.

\section{References}

[1] (a) Chattopadhyay, B.; Gevorgyan, V. Angew. Chem., Int. Ed. 2012, 51,862 .

(b) Urankar, D.; Pinter, B.; Pevec, A. Inorg. Chem. 2010, 49, 4820. (c) Struthers, H.; Mindt, T. L.; Schibli, R. Dalton. Trans. 2010, 39, 675 .

(d) Wang, R.; Wang, Y.; Bian, Y.; Zhang, P. Chin. J. Org. Chem. 2020, 40, 398 (in Chinese).

(王冉冉, 王岩, 边彦青, 张萍, 有机化学, 2020, 40, 398.)

[2] (a) Chu, C.; Liu, R. Chem. Soc. Rev. 2011, 40, 2177.

(b) Lau, Y. H.; Rutledge, P. J.; Watkinson, M.; Todd, M. H. Chem. Soc. Rev. 2011, 40, 2848.

(c) Johnson, T. C.; Totty, W. G.; Wills, M. Org. Lett. 2012, 14, 5230.

[3] (a) Astruc, D.; Liang, L.; Rapakousiou, A.; Ruiz, J. Chem. Res. 2012, 45, 630

(b) Muller, T.; Bräse, S. Angew. Chem., Int. Ed. 2011, 50, 11844.

[4] (a) Wang, W.; Peng, X.; Wei, F.; Tung, C.-H.; Xu, Z. Angew. Chem., Int. Ed. 2016, 55, 649

(b) Cheung, K. P. S.; Tsui, G. C. Org. Lett. 2017, 19, 2881.

[5] (a) Thirumurugan, P.; Matosiuk, D.; Jozwiak, K. Chem. Rev. 2013, 113,4905 .

(b) Wang, K.; Chen, M.; Wang, Q.; Shi, X.; Lee, J. K. J. Org. Chem. 2013, 78, 7249.

[6] (a) Jiang, Y.; Hansen. T. V. Bioorg. Med. Chem. Lett. 2011, 21 , 1626.

(b) Xu, X.; Guo, S.; Zhang, J.; Chen, Y.; Kang, Y.; Liu, N.; Liu J.; Luo, C.; Chen, S.; Chen, H. Chin. J. Org. Chem. 2020, 40, 1345 (in Chinese).
(徐晓明，郭思岐，张静，陈彦蹈，康亚青，刘娜，刘俊芳，罗成， 陈示洁, 陈华, 有机化学, 2020, 40, 1345.)

[7] (a) Quan, X. J.; Ren, Z. H.; Wang, Y. Y.; Guan, Z. H. Org. Lett. 2014, 16, 5728 .

(b) Chen, C. Y.; Lee, P. H.; Lin, Y. Y.; Yu, W. T.; Hu, W. P.; Hsu, C. C.; Lin, Y. T.; Chang, L. S.; Hsiao, C. T.; Wang, J. J.; Chung, M. L. Bioorg. Med. Chem. Lett. 2013, 23, 6854.

[8] (a) Kolb, H. C.; Finn, M. G.; Sharpless, K. B. Angew. Chem., Int. Ed. 2001, 40, 2004.

(b) Rostovtsev, V. V.; Green, L. G.; Fokin, V. V.; Sharpless, K. B. Angew. Chem., Int. Ed. 2002, 41, 2596.

(c) Moses, J. E.; Moorhouse, A. D. Chem. Soc. Rev. 2007, 36, 1249.

(d) Tiwari, V. K.; Mishra, B. B.; Mishra, K. B.; Mishra, N.; Singh, A. S.; Chen, X. Chem. Rev. 2016, 116, 3086.

(e) Wang, C.; Zhou, F.; Zhou J. Chin. J. Org. Chem. 2020, 40, 3065 (in Chinese).

(王才, 周峰, 周剑, 有机化学, 2020, 40, 3065.)

[9] Kalisiak, J.; Sharpless, K. B.; Fokin, V. V. Org. Lett. 2008, 10, 3171.

[10] Zhang, Y.; Li, X.; Li, J.; Chen, J.; Meng, X.; Zhao, M.; Chen, B. Org. Lett. 2012, 14, 26.

[11] Kamijo, S.; Jin, T.; Huo, Z. B.; Yamamoto, Y. J. Am. Chem. Soc. 2003, 125, 7786 .

[12] Phanindrudu, M.; Tiwari, D. K.; Aravilli, V. K.; Bhardwaj, K. C.; Sabapathi, G.; Likhar, P. R. Eur. J. Org. Chem. 2016, 27, 4629.

[13] Shen, T.; Huang, X.; Liang, Y.-F.; Jiao, N. Org. Lett. 2015, 17, 6186.

[14] Chen, J.; Liang, T.; Zhao, H.; Lin, C.; Chen, L.; Zhang, M. Org. Biomol. Chem. 2019, 17, 4843.

[15] Bao, P. L.; Yue, H.; Meng, N.; Zhao, X.; Li, J.; Wei, W. Org. Lett. 2019, 21, 7218 .

[16] Bao, P. L.; Meng, N.; Lv, Y.; Yue, H.; Li, J.; Wei, W. Org. Chem. Front. 2019, 6, 3983.

[17] Virant, M.; Košmrlj, J. J. Org. Chem. 2019, 84, 14030.

[18] Cui, F.; Chen, J.; Mo, Z.; Su, S.; Chen, Y.; Ma, X.; Tang, H.; Wang, H.; Pan, Y.; Xu, Y. Org. Lett. 2018, 20, 925.

[19] Jana, S.; Thomas, J.; Dehaen, W. J. Org. Chem. 2016, 81, 12426.

[20] Chen, Y. F.; Nie, G.; Zhang, Q.; Ma, S.; Li, H.; Hu, Q. Q. Org. Lett. 2015, 17, 1118.

[21] Liu, Y.; Nie, G.; Zhou, Z.; Jia, L.; Chen, Y. J. Org. Chem. 2017, $82,9198$.

[22] Kumar, N.; Ansari, M. Y.; Kumart, A. Chem. Commun. 2018, 54, 2627.

[23] Wei, F.; Li, H.; Song, C.; Ma, Y.; Zhou, L.; Tung, C.-H.; Xu, Z. H Org. Lett. 2015, 17, 2860.

[24] Wang, W. G.; Peng, X. L.; Wei, F.; Tung, C. H.; Xu, Z. H. Angew. Chem., Int. Ed. 2016, 55, 649.

[25] (a) Wang, W.; Wei, F.; Ma, Y.; Tung, C.-H.; Xu, Z. H. Org. Lett. 2016, 18,4158 .

(b) Wang, W.; Lin, Y.; Ma, Y.; Tung, C.-H.; Xu, Z. H. Org. Lett. 2018, 20, 2956.

[26] Shang, J. Q.; Fu, H.; Li, Y.; Yang, T.; Gao, C. Z.; Li, Y. M. Tetrahedron 2019, 75, 253.

[27] (a) Chen, Y.; Liu, Y.; Petersena, J. L.; Shi, X. Chem. Commun. 2008, 3254.

(b) Liu, Y.; Yan, W.; Chen, Y.; Petersen, J. L.; Shi, X. Org. Lett. 2008, 10, 5389.

(c) Wang, X.; Sidhu, K.; Zhang, L.; Campbell, S.; Haddad, N.; Reeves, D. C.; Krishnamurthy, D.; Senanayake, C. H. Org. Lett. 2009, 11, 5490 .

(d) Zhang, C.; Zheng, L.; Yan, Q.; Hu, Q.; Jia, F.; Chen, Y. ChemistrySelect 2018, 3, 10277.

[28] Aruri, H.; Singh, U.; Sharma, S.; Gudup, S.; Bhogal, M.; Kumar, S.; Singh, D.; Gupta, V. K.; Kant, R.; Vishwakarma, R. A.; Singh. P. P. J. Org. Chem. 2015, 80, 1929 .

[29] Deng, X. C.; Lei, X.; Nie, G.; Jia, L. H.; Li, Y. X.; Chen, Y. F. J. Org. Chem. 2017, 82, 6163.

[30] Zhang, L. L.; Yi, H.; Wang, J.; Lei, A. W. J. Org. Chem. 2017, 82, 
10704.

[31] Wu, J.; Zhou, Y.; Zhou, Y.; Chiang, C. W.; Lei, A. W. ACS Catal. 2017, 7, 8320.

[32] Berthold, D.; Breit, B. Org. Lett. 2018, 20, 598.

[33] Luo, G. L.; Sun, C. Y.; Li, Y.; Li, X. X.; Zhao, Z. RSC Adv. 2018, 8 , 27610.

[34] Chen, Z.; Cao, G.; Song, J.; Ren, H. Chin. J. Chem. 2017, 35, 1797.

[35] Hanselmann, R.; Job, G. E.; Johnson, G.; Lou, R.; Martynow, J. G.; Reeve, M. M. Org. Process Res. Dev. 2010, 14, 152.

[36] van Berkel, S. S.; Brauch, S.; Gabriel, L.; Henze, M.; Stark, S.; Va-silev, D.; Wessjohann, L. A.; Abbas, M.; Westermann, B. Angew. Chem., Int. Ed. 2012, 51, 5343.

[37] (a) Fçhlisch, B.; Flogaus, R. Synthesis 1984, 734.

(b) Bangalore, J.; Llavona, L.; Concellon, J. M.; Yus, M. J. Chem. Soc., Perkin Trans. 1 1991, 297.

[38] (a) Chen, Z.; Yan, Q.; Liu, Z.; Xu, Y.; Zhang, Y. Angew. Chem., Int. Ed. 2013, 52, 13324. (b) Chen, Z.; Yan, Q.; Yi, H.; Liu, Z.; Lei, A.; Zhang, Y. Chem.-Eur. J. 2014, 20, 13692.

[39] Cai, Z.-J.; Lu, X.-M.; Zi, Y.; Yang, C.; Shen, L.-J.; Li, J.; Wang, S.-Y.; Ji, S.-J. Org. Lett. 2014, 16, 5108.

[40] Guru, M. M.; Punniyamurthy, T. J. Org. Chem. 2012, 77, 5063.

[41] Chen, Z.; Yan, Q.; Liu, Z.; Zhang, Y. Chem.-Eur. J. 2014, 20, 17535.

[42] (a) Wan, J.-P.; Cao, S.; Liu, Y. J. Org. Chem. 2015, 80, 9028.

(b) Thomas, J.; Goyvaerts, V.; Liekens, S.; Dehaen, W. Chem.-Eur. J. 2016, 22, 9966.

[43] Li, Y.-J.; Li, X.; Zhang, S.-X.; Zhao, Y.-L.; Liu, Q. Chem. Commun. 2015, 51, 11564 .

[44] Wang, S.; Yang, L.-J.; Zeng, J.-L.; Zheng, Y.; Ma, J.-A. Org. Chem. Front. 2015, 2, 1468.

[45] Kiselyov, A. S. Tetrahedron Lett. 2006, 47, 2631.

[46] Ahamad, S.; Kant, R.; Mohanan, K. Org. Lett. 2016, 18, 280. 